NASA Technical Memorandum 101363

IEPC-88-091

\title{
Experimental Evaluation of Resistojet Thruster Plume Shields
}

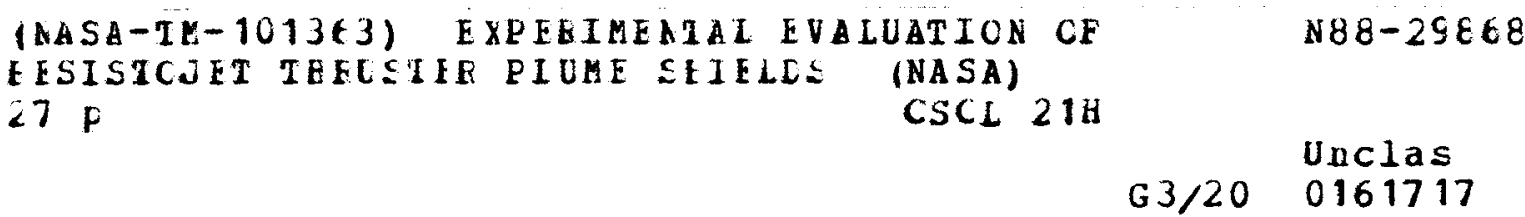

Lynnette M. Carney

Lewis Research Center

Cleveland, Ohio

and

Allan B. Bailey

Calspan Corporation

Arnold Engineering Development Center

Arnold Air Force Base, Tennessee

Prepared for the

20th International Electric Propulsion Conference cosponsored by the DGLR, AIAA, and JSASS

Garmisch-Partenkirchen, W. Germany, October 3-6, 1988 


\title{
EXPERIMENTAL EVALUATION OF RESISTOJET THRUSTER PLUME SHIELDS
}

\author{
Lynnette M. Carney \\ National Aeronautics and Space Administration \\ Lewis Research Center \\ Cleveland, $\mathrm{OH} 44135$
}

and

\author{
Allan B. Bailey \\ Calspan Corporation \\ Arnold Engineering Development Center \\ Arnold Air Force Base, TN 37389
}

\begin{abstract}
The exhaust of an engineering model resistojet has been investigated using rotary pitot probes and a rotary quartz crystal microbalance. The resistojet operated on $\mathrm{CO}_{2}$ propellant at a mass flow rate of $0.29 \mathrm{~g} / \mathrm{sec}$ in both heated and unheated flows. Measurements of local flow angles in the near field of a conical plume shield indicated that the shield was not wholly effective in confining the flow to the region upstream of its exit plane. However, the absolute levels of the measured mass flux into the backflow region were very low, on the order of $7 \times 10^{-7} \mathrm{~g} / \mathrm{cm}^{2}-\mathrm{sec}$ or less. The use of a circular disk at the exit plane of the existing conical shield showed some benefit in decreasing the amount of backflow by a factor of 2 . Lastly, a detached shield placed upstream of the resistojet exit plane demonstrated a small degree of local shielding for the region directly behind it.
\end{abstract}

\section{LIST OF SYMBOLS}

$\begin{array}{ll}A & \text { Nozzle area, } \mathrm{m}^{2} \\ D^{*} & \text { Nozzle throat diameter, } \mathrm{m} \\ D_{e} & \text { Nozzle exit diameter, } \mathrm{m} \\ D_{p} & \text { Pitot probe orifice diameter, } \mathrm{m} \\ D_{s} & \text { Conical shield exit diameter, } \mathrm{m} \\ K & \text { Constant for Equation }(2) \\ M & \text { Mach number } \\ \dot{M} & \text { Mass flux, } \mathrm{g} / \mathrm{cm}^{2}-\mathrm{sec} \\ \dot{m} & \text { Mass flow rate, } \mathrm{g} / \mathrm{sec} \\ P & \text { Gas pressure, } \mathrm{N} / \mathrm{m}^{2} \\ P_{o} & \text { Measured pitot pressure, } \mathrm{N} / \mathrm{m}^{2} \\ r & \text { Radial distance from thruster exit plane to center of } \mathrm{QCM} \text { crystal, } \mathrm{m} \\ R & \text { Radius from plume centerline, } \mathrm{m} \\ T & \text { Gas temperature, } \mathrm{K} \\ U & \text { Gas velocity, } \mathrm{m} / \mathrm{sec} \\ z & \text { Axial distance from conical shield exit plane, } \mathrm{m} \\ \gamma & \text { Specific heat ratio } \\ \theta & \text { Angle from plume centerline, deg } \\ \mu & \text { Viscosity, N-sec/m }{ }^{2} \\ \rho & \text { Gas density, number } / \mathrm{m}^{3} \\ \phi & \text { Nozzle half angle, deg } \\ \Omega & \text { Solid angle, steradians }\end{array}$


Sub- or Superscript Notation

$\begin{array}{ll}e & \text { Denotes exit plane conditions } \\ i & \text { Denotes inlet conditions } \\ \text { max } & \text { Denotes maximum } \\ o & \text { Denotes stagnation conditions } \\ * & \text { Denotes sonic conditions } \\ \infty & \text { Denotes freestream static } \\ 2 & \text { Denotes conditions downstream of normal shock }\end{array}$

\section{INTRODUCTION}

The multipropellant resistojet thruster has been baselined for auxiliary propulsion applications onboard the Space Station Freedom (Level B Space Station Control Board Directive). It offers low thrust propulsion for drag make-up and also the capability for propulsive, or non-propulsive venting of waste gases. A NASA-sponsored study ${ }^{1}$ has indicated that use of the resistojet in conjunction with a hydrogen/oxygen primary propulsion system is advantageous in terms of both development and operational cost. A 48 percent decrease in total propulsion system life cycle cost over a ten year period was predicted over a stand-alone system. However, as with the high thrust propulsion system and other sources of effluents, the exhaust flow field of the resistojet must be well defined prior to integration because of the potential impacts that the plume may have on station science and technology activities. Impacts of primary concern include induced environmental contamination during quiescent periods and mass deposition on sensitive surfaces. Thermal loading and disturbance torques caused by plume impingement may also become important, depending on the space station architecture.

A number of diagnostic techniques for the measurement of fundamental plume properties are well established.2,3 Experimental studies of pure gas, conical nozzle expansions into hard vacuum have investigated the effects of nozzle area ratio and lip geometry, facility pressure, condensation, and inadequate cryopumping in the backflow region. Further, these experiments demonstrated that conventional numerical techniques alone are insufficient to accurately predict plume flow field characteristics, particularly at the high angle regions of interest for contamination studies. Preliminary investigations of the resistojet plume have also been reported previously.4,5 Mass flux measurements in the exhaust of a laboratory resistojet operating on $\mathrm{CO}_{2}$ propellant at $298 \mathrm{~K}$ indicated that the flow expanded beyond a calculated limiting turning angle using continuum methods. The amount, however, represented only a very small fraction of the total thruster throughput.

The purpose of the experimental work described herein was to gain more insight into the backflow issue of resistojet plumes. An experimental investigation was conducted at the Arnold Engineering Development Center (AEDC) to measure the level of backflux from an engineering model resistojet developed for space station application and also to evaluate the effectiveness of plume shields in preventing or minimizing the backflux. Three specific shield types were evaluated: (1) a large, conical plume shield integrated in the design of the engineering model thruster6; (2) circular disks positioned at the exit plane of the conical shield with the intent of simulating an infinitely thick lip; and (3) a flat plate placed upstream of the thruster exit, well into the free molecule flow regime of the resistojet plume. 
This paper presents an initial evaluation of the experimental data obtained for the resistojet plume. Details of the measurement techniques and experimental hardware are provided, along with a brief description of the test facility. The near field plume character of the resistojet is described in terms of dynamic pressure profiles and local flow angle variation for the different shield configurations. Other data to be presented include estimates of Mach number variation along plume centerline, radial dynamic pressure profiles for heated and unheated flow, and mass flux variation in the plume as a function of radial and axial distance. Absolute values of measured mass flux are also compared with experimental results of related investigations.

\section{APPARATUS}

\section{Engineering Model Resistojet}

The resistojet thruster used in this investigation was an engineering model ( Figure 1 ), designed and fabricated by a Rocketdyne-Technion industrial team under contract to the NASA Lewis Research Center. ${ }^{6}$ In the space station application, the resistojet propulsion system would utilize waste gases from the Environmental Control and Life Support Systems, Materials Technology Laboratory, and Attached Payloads. Potential resistojet propellants for space station include inert gases, water vapor, carbon dioxide, cabin air, methane, and hydrogen. Since the propellant supply would be readily available, performance was not a major design criterion. Instead, the design goals were a $10000 \mathrm{hr}$ lifetime and a multipropellant capability. Figure 1(a) displays a photograph of the resistojet, while a cutaway schematic of its interior is illustrated in Figure 1 (b). The propellant passes through a mutlichannel heat exchanger which, in turn, is conductively and radiatively heated from a double helix, sheathed heater. Several layers of radiation shields surround the heater assembly. Grain-stabilized platinum was used as fabrication material for the heater, heat exchanger, and nozzle components because it has demonstrated adequate life and propellant compatibility under high temperature operation. The outer shroud is made of inconel.

The nozzle region incorporates a $25^{\circ}$ half angle cone with a throat diameter of $0.102 \mathrm{~cm}(0.040 \mathrm{in})$, followed by a trumpet flare. The intention of the flared portion is to provide for boundary layer growth and to direct the flow in the thrust direction. The trumpet flare also provides additional structural support to the resistojet body. Its exit diameter is $5.07 \mathrm{~cm}$ (1.998 in), giving an overall nozzle area ratio of 2500 . A large $45^{\circ}$ cone is attached at the end of the trumpet flare as a plume shield. The small holes which are visible (Fig. 1(a)) in the edge between the flare and the shield are fail-operational vents which ensure that, in the event of propellant leakage, all gas would vent in the thrust direction. Reference 6 provides complete details of the design and fabrication of the engineering model resistojet. Performance data for a variety of propellants and information of the thermal characteristics of the thruster may be found in Reference 7.

\section{Plume Shield Configurations}

Figure 2 illustrates the various shield configurations used in this investigation. As shown previously, a large conical plume shield was integrated into the engineering model design. The large cone has a half angle of $45^{\circ}$ and an exit diameter of $9.65 \mathrm{~cm}$ ( 3.80 in ). It was not expedient to remove this shield to determine its relative effectiveness over the nozzle alone. A second configuration simulated an infinitely thick lip on the existing conical shield. Thin concentric disks made of stainless steel were placed at the exit of the conical shield as illustrated in Figure 2(a). Two circular disks were tested, having outer diameters of 17.8 and $22.9 \mathrm{~cm}$, respectively. Lastly, a detached shield, placed at a distance $10.8 \mathrm{~cm}$ upstream of the conical shield exit plane, was also tested to measure the degree of local shielding which could be obtained. The detached shield was a thin 
stainless steel plate which extended outward $33.7 \mathrm{~cm}$ from the centerline as illustrated in Figure 2 (b).

\section{Instrumentation}

There are a number of diagnostic techniques available for the local, quantitative measurement of fundamental flow field properties. However, the backflux region of the resistojet plume, because of its low absolute number density and steep property gradients, precludes the immediate adaptation of a variety of non-intrusive optical techniques which are limited to densities well above $1011 / \mathrm{cm}^{3}$. Consequently, two intrusive probe techniques, the pitot probe and the Quartz Crystal Microbalance, were utilized to determine the plume properties of interest.

The pitot probe is a simple, effective technique for the measurement of dynamic pressure ( $\rho U^{2}$ ) and local flow angle. As described in Reference 2, it consists simply of an open-ended, flat-faced tube which is aligned with the open end facing toward the gas flow. The other end of the tube is attached to an absolute pressure transducer. It has been shown ${ }^{2}$ that the pitot pressure is an excellent means of obtaining the local velocity vector as it is extremely sensitive to local flow angle variation. Further, assuming that the gas is ideal and that the change in flow properties across the bow shock can be described by the Rankine-Hugoniot relations, the flow Mach number may also be derived by relating the measured pitot pressure Po' to the reservoir pressure Po using the following relationship:

$$
P_{o} / P_{o}^{\prime}=\left[\left(2 \gamma M_{\infty}^{2}-\gamma+1\right) /(\gamma+1)\right]^{1 / \gamma 1}\left\{\left[2+(\gamma-1) M_{\infty}^{2}\right] /\left[(\gamma+1) M_{\infty}^{2}\right]\right\} \gamma \gamma 1
$$

The above relationship is limited to isentropic flow conditions and was only used to obtain Mach number estimates along the plume centerline.

For high Mach numbers, the dynamic pressure is given by 2

$$
\rho_{\infty} U_{\infty}^{2}=2 P_{o}^{\prime} / K
$$

where $K=1.9$ for the flow conditions of interest ( $\gamma \approx 1.4$ and $M>5$ ).

The pitot probes used in this investigation had orifice diameters of $0.152 \mathrm{~cm}(0.06$ in ) and $0.635 \mathrm{~cm}$ ( $0.25 \mathrm{in})$. The absolute pressure transducers were calibrated against a base standard and ranged in pressure response from $1 \times 10^{-2}$ to $4 \times 10^{5} \mathrm{~N} / \mathrm{m}^{2}\left(1 \times 10^{-4}\right.$ to $3 \times 10^{3}$ Torr ). A continuous record of the output of these gauges was maintained such that gauge-to-gauge comparisons in regions of pressure overlap could be made. In this way, any change in gauge performance could be determined and accounted for. Probe characteristics, e.g., temperature and Reynolds number, affect the interpretation of the measured pressure. However, the uncertainty between relative pitot pressures is probably less than ten percent. Bayard-Alpert ionization gauges, together with Granville-Phillips Convectron gauges, were also used for pressure measurements from $1 \times 10^{-4}$ to $1 \times 10^{-1}$ $\mathrm{N} / \mathrm{m}^{2}\left(1 \times 10^{-6}\right.$ to $1 \times 10^{-3}$ Torr $)$.

The Quartz Crystal Microbalance (QCM) is a well established technique for contamination monitoring and the mapping of exhaust flow fields.2-3,8-9 Basically, the QCM consists of a matched pair of precision, optically polished crystals which are cryogenically cooled with liquid nitrogen to temperatures sufficient to collect mass on one of the crystals (sensor crystal) while the other crystal serves as a reference. The QCM relates a change in beat frequency between the two crystals to the amount of mass loading, or mass flux. 
Pertinent details of the QCM used in this investigation are listed in Table I. Previous calibration ${ }^{2}$ of the QCM in a flow of known mass flux indicated a measurement uncertainty of thirty percent. Based on this information, it has been concluded that this is a reasonable measure of the uncertainty of the measured mass flux for the present study.

\section{Test Facility and Experimental Set-up}

The plume experiments were conducted in the 4-by10-ft Research Vacuum Chamber (RVC) at AEDC which has an inner diameter of approximately $1.1 \mathrm{~m}$ and is 4.3 $\mathrm{m}$ long. It is equipped with a mechanical roughing pump and two oil diffusion pumps. However, the majority of the pumping is achieved through the use of cryogenically-cooled $(77 \mathrm{~K}$ ) baffles which line the inner surface. Throughout the experiments, the facility maintained a background pressure on the order of $1 \times 10^{-3}$ to $5 \times 10^{-3} \mathrm{~N} / \mathrm{m}^{2}$ ( $8 \times 10^{-6}$ to 4 x 10-5 Torr ).

The engineering model resistojet was mounted on a dual axis traversing mechanism as illustrated in Figure 3. The thruster unit was supplemented with additional radiation shielding as shown. Also shown in the figure are the $17.8 \mathrm{~cm}$ diam. circular disk and various instrumentation. The cryo-cooled plate which surrounds the body of the resistojet was removed after initial testing because it interfered with the time it took to thermally stabilize the thruster body and because it provided a scattering surface as it could not be kept cold enough to pump $\mathrm{CO}_{2}$. The centerline of the plume shield exit plane, as opposed to the true nozzle exit plane, was used as the zero reference for all probe measurements. Both the QCM and the pitot probe were mounted on motor-driven, rotary mechanisms. The movement of the thruster and probes could be controlled manually or with a computer. Changes in the position of the probes with respect to the nozzle centerline were accomplished by positioning the probes at a fixed location and moving the resistojet. The angular orientation of the probes was then adjusted using the rotary devices.

The mass flow rate was obtained with simultaneous measurements from both Matheson and Fischer-Porter flow meters while the inlet pressure was measured via a pressure tap upstream of the resistojet. The heater current was obtained using a $1 \mathrm{ohm}$ shunt.

\section{PROCEDURE}

The pitot probe and QCM were accurately positioned both axially and radially with respect to the shield exit plane prior to the facility pump down. It was not possible to detect any movement of the probe or nozzle as a result of chamber evacuation. However, as the chamber was cooled cryogenically and the thruster heated, axial movement of the lip of the conical plume shield was observed. An accurate measurement of this growth was determined by tracking the nozzle axially until the lip was once again aligned with the probe. This correction was made for all test conditions. Although it was not possible to measure the radial growth of the nozzle, it was determined from complete radial surveys in the exit plane that the thruster axis did not move radially as the thruster components were heated.

Depending upon the test requirements, it was found that between 2 and 3 hours were required to bring the chamber and resistojet to the desired operating conditions, i.e., thruster temperature, gas temperature, and cryoliner temperature to a steady state condition. Sufficient temperature and pressure instrumentation was available to monitor the performance of the complete chamber/thruster configuration. 
In keeping with earlier performance evaluations of the resistojet using $\mathrm{CO}_{2}$ propellant, 7 a mass flow rate of about $0.29 \mathrm{~g} / \mathrm{sec}$ was selected for both the unheated and heated flow tests. For the heated flow tests, the heater current was set to $23 \mathrm{~A}$ giving a steady state heater power of $405 \mathrm{~W}$. Table II lists the resistojet operating conditions used in this investigation along with typical performance parameters. In order to ensure safe operation of the thruster without component overheating, thermocouples positioned at three locations within the containment shroud were continuously monitored throughout the experiments ( Fig. 1(a)).

Pitot probe measurements were obtained on centerline as a function of axial distance for both unheated and heated flow. Pitot pressure profiles along a radius were then obtained at various distances downstream of the exit plane. Complete radial surveys were also made at discrete measurement locations in order to obtain the local flow velocity vectors.

It was originally intended to use the rotary pitot probe to obtain the local flow angle in the backflux region so that efficient use of the QCM could be possible in the mass flux measurements. However, as will be described in a later section, the pitot probes could not accurately determine flow angle in the region upstream of the circular disk configurations. Consequently, complete rotary surveys of the QCM had to be made at each measurement location. This situation limited the amount of information which could be obtained for a given test condition. It was decided to make a number of the axial mass flux measurements by setting the QCM at a fixed radial distance from the plume centerline $(23.8 \mathrm{~cm})$ and at a fixed angular orientation to the thrust axis ( $146 \mathrm{deg}$ ). Lastly, the Bayard-Alpert ionization gauge was also used to measure axial pressure variation at large radial distances.

\section{RESULTS AND DISCUSSION}

This section presents initial results in the experimental investigation of the flux from an engineering model resistojet and the use of plume shields. First, the near field of the plume is described for unheated and heated flow in terms of dynamic pressure variation and local flow angle, along with estimates of the centerline Mach number variation. Mass flux data taken with the rotary QCM is presented as a function of angle off plume centerline for the resistojet, with and without a circular disk shield. Absolute values of measured mass flux are also compared with experimental results of related investigations.

\section{Pitot Probe Surveys}

Figure 4 displays the axial variation of pitot pressure along the plume centerline for heated flow, plotting alternate data points from several separate axial scans. The figure demonstrates the basic repeatability of both the measurement technique and thruster operation on a day-to-day basis. Although not shown, the measured centerline pitot pressure was found to be independent of the nozzle/shield configuration. Figure 5 illustrates the centerline Mach number variation for heated and unheated flow. Using Equation (1) and its corresponding assumptions, the Mach number is estimated for two values of the specific heat ratio, $\gamma=1.3$ and 1.4. For carbon dioxide nozzle flow with stagnation temperatures between 300 and $700 \mathrm{~K}$, it has been shown 2,10 that an effective $\gamma$ of 1.4 is appropriate as the $\mathrm{CO}_{2}$ is vibrationally frozen. It is indeterminate as to which value is appropriate for the heated flow case ( where $T_{o}$ should be $\geq 700 \mathrm{~K}$ ), although $\gamma=$ 1.3 has been shown to compare reasonably well with numerical predictions in for underexpanded nozzles with high throat Reynolds numbers $\left(\approx 10^{4}\right) .11$ The possibility of condensation has not been accounted for in this analysis. 
Figure 6 displays pitot pressure variation across the plume centerline for heated flow at a number of axial distances downstream of the shield exit plane. At the low background pressures utilized for the plume measurements, the nozzle was devoid of shocks. However, at pressures above $3 \mathrm{~N} / \mathrm{m}^{2}$ ( $2 \times 10^{-2}$ Torr ), a pronounced spike was observed in all radial profiles, indicating an outwardly expanding shock generated in the nozzle interior. There is a slight asymmetry to the flow, as shown in the profiles close to the exit plane (Fig. 6(a) ). This asymmetry is probably due to the creation of a hot spot caused by a slight misalignment of the outer shroud and nozzle during assembly. ${ }^{7}$ The off-center humps which are also present in the profiles are indicative of the transition from isentropic core flow to boundary layer flow. As shown in the profiles, a significant portion of the nozzle flow consists of boundary layer. Further downstream of the exit plane ( Figure 6(b) ) the inviscid core dissipates and the flow becomes more symmetric. The continuity of the profiles suggests that there is no flow separation between the core and boundary layer.

The variation of measured pitot pressure with flow angle enables the use of the pitot probe for local velocity vector measurements. Examples of the probe response with angle to thrust axis are illustrated in Figure 7. In the first case ( Fig. 7(a) ), the probe is located at a distance of $0.12 \mathrm{~cm}$ downstream of the exit plane and $4.5 \mathrm{~cm}$ from centerline. Using the angle at which the peak occurs as the local flow angle ${ }^{2}$, the measured local flow angle is $62.5 \mathrm{deg}$ with respect to centerline. A similar pressure profile is shown in Fig. 7(b) except in this case the probe is located further off centerline. Here the profile is highly confined and asymmetric about the peak pressure at $85 \mathrm{deg}$. This profile implies that the flow at this measurement location is in free molecule flow.

Figure 8 displays the bulk of the pitot probe flow angle measurements obtained for the resistojet with and without a circular disk as a function of radial and axial distance. The locations of the edges of the trumpet flare, the existing plume shield, and the circular disk are marked in the figure. The flow does not remain parallel to the $45^{\circ}$ conical shield as the local flow angle at the edge of the shield is approximately 20 degrees greater than that of the shield. The $17.8 \mathrm{~cm}$ disk placed at the edge of the existing shield did not have a marked effect on local flow angle variation except that it confined the boundary layer flow along its surface until the flow reached its lip. The degree of local scattering off of the disk surface was not investigated in detail. Also, in the case of the added circular disk, it was not possible to obtain accurate measurements of flow angle for the measurement locations upstream of the exit plane (Fig. 8(b) ) even at radial distances exceeding the edge of the disks. This qualitatively suggests a reduction in backflow but, as will be shown later, there is still evidence of directed flow in the region upstream of the concentric disks. The lack of pitot pressure profile data in this region is simply a limitation of the particular probe/transducer arrangement used. As mentioned previously, the minimum detectable pitot pressure which could be measured was approximately $1 \times 10^{-2} \mathrm{~N} / \mathrm{m}^{2}\left(1 \times 10^{-4}\right.$ Torr $)$. However, in practical application, maximum pitot pressures of at least $4 \times 10^{-2} \mathrm{~N} / \mathrm{m}^{2}(3 \mathrm{x}$ $10^{-4}$ Torr ) were needed to determine the local flow angle with reasonable certainty. A free molecule pressure probe 2 is required to provide a better description of the flow pattern in the backflow region. Finally, the pronounced kinks in the flow angle profiles deserve comment. It is unlikely that they denote the transition from inviscid core to boundary layer flow as they occur too far off center. Most probably the kinks are a result of the step variation from the edge of the trumpet flare (at an angle approaching $90^{\circ}$ ) and the conical shield ( half angle of $45^{\circ}$ ), but there are insufficient data to document this possibility.

Figure 9 plots the dynamic pressure variation of the flow as a function of radial distance at a distance of $0.64 \mathrm{~cm}$ downstream of the shield exit plane, with and without an added circular disk. The profiles are based on the maximum pitot pressure, that is, the pitot 
pressure measured at the local flow angle. The locations of the edge of the trumpet flare, conical shield exit radius, and circular disk outer radius are marked in the figure. The dynamic pressure at radial distances beyond $7 \mathrm{~cm}$ is slightly higher with the added circular disk. Although the increase is slight, the difference exceeds the relative measurement uncertainty and serves as a further indication that the added circular disk aids in the minimization of backflow. A previous investigation 2 of thin and thick lip nozzle configurations did not find a dependency of dynamic pressure on lip geometry at the nozzle exit. However, the lip thickness in that investigation was approximately one half of the pitot probe diameter.

\section{Ionization Gauge Measurements}

The Bayard-Alpert ionization gauge was also used to survey the backflow region of the engineering model resistojet. Figure 10 presents axial pressure variation for a number of radial positions. The ion gauge is normal to the thrust axis for all measurements (i.e., at $90^{\circ}$ with respect to the plume centerline ). The ion gauge was also compared against a second gauge which looked away from the thruster lip. As the relative gauge position crosses through the exit plane there is a rapid decrease in the measured pressure. The ion gauge measurements support the previous discussion in that there is highly directional flow coming from the nozzle lip region at flow angles well beyond that of the conical shield $\left(45^{\circ}\right)$. Using $1 \times 10^{-3} \mathrm{~N} / \mathrm{m}^{2}\left(8 \times 10^{-6} \mathrm{Torr}\right)$ as a point of reference for the backflux region gives a background molecular number density of $2 \times 1011 / \mathrm{cm}^{3}$.

\section{Mass Flux Measurements}

As mentioned previously, the rotary pitot probe was unsuccessful in documenting the local flow angle in the region upstream of the various shield configurations. Consequently, complete rotary surveys of the QCM had to be made at each measurement location. Because of the extreme sensitivity of the device, it was often not possible to complete a rotary survey before the sensor crystal was overloaded with condensed $\mathrm{CO}_{2}$. The surface had to be cleaned by warming up the QCM and then re-cooling. Figure 11 plots measured mass flux for the rotary QCM as a function of angle to thrust axis at the same location for two separate surveys. The repeatability of the data at the peak falls within the estimated uncertainty of the measurement technique. Complete rotary scans of the QCM were obtained as a function of axial distance at a fixed radius from the plume centerline as shown in Figure 12. Using the sensor crystal area of $0.316 \mathrm{~cm}^{2}$, the data are presented in units of $\mathrm{g} / \mathrm{sec}$ in order to be consistent with Reference 2 . For the most part, the data fit a well-defined cosine distribution near the peak which is indicative of a directed flow into the backflux region. The angle at which the maximum mass flux is obtained is again assumed to be the local flow angle. The average background level of mass flux to the QCM in the region upstream of the thruster exit plane was on the order of $2-4 \times 10^{-8}$ $\mathrm{g} / \mathrm{sec}$. Contributions to this background level of mass flux included scattering off of the hot surfaces of the thruster and mounting configuration, particularly in the data obtained without a circular disk, because the upstream cryopanel ( Fig. 3 ) had to be removed after initial tests. Although the presence of nonpumping surfaces is more representative of an actual spaceflight configuration, it made interpretation of some of the QCM data difficult. Mass flux tests in which there was strong evidence of scattering phenomena occurring were not used in the following data analysis. The peak mass flux data from the rotary scans are plotted in Figure 13 as a function of angle off centerline for the resistojet, with and without the various shield configurations. It appears that the relative benefit of increasing the conical shield lip thickness further with the addition of a circular disk is less than a factor of 2. Figure 14 presents a similar result with a plot of mass flux data as a function of axial distance at a constant radial location. Table III compares measured mass flux values of the engineering model resistojet with similar investigations of backflux from monopropellant and bipropellant thrusters. In order to account for differences in QCM mounting 
arrangements, the data are presented in terms of mass flux per unit solid angle. It is noteworthy that the absolute levels of mass flux are at least one to two orders of magnitude lower than the higher thrust propulsion systems.9,12 The relative amount of backflow from the resistojet nozzle configuration is also compared to that of a standard conical nozzle by relating the level of measured mass flux at discrete angles off centerline to the thruster total mass flow rate. The ratio of local mass flux to the total mass flow rate for the resistojet is lower than that of the conical nozzle 2 by factors of $2-8$ which suggests that the existing conical shield may be of some value in minimizing backflux. As a conservative estimate, less than 0.2 percent of the total resistojet mass flow expands into the backflux hemisphere.

\section{Detached Shield Configuration}

Only a limited amount of data was obtained for the detached shield arrangement shown in Figure 2 (b). Figure 15 presents measured mass flux as a function of angle to the thrust axis for discrete locations in front of and behind the detached shield. In Figure 15 (a) the QCM is located just beyond the edge of the shield at $\mathrm{R}=39 \mathrm{~cm}$. Although the mass flux behind the shield is slightly lower than in front, it appears that the measured mass flux is a result of random scatter rather than a directed flow as there is no apparent peak in the mass flux levels. Figure 15 (b) presents a similar result for various radial distances within the dimensions of the detached shield. There is some indication that the presence of a nonpumping surface in the backflow region contributes to a recirculatory flow field just ahead of it. The effects of nonpumping surfaces in the backflux region has been documented previously. 2 It is suggested that the detached shield contributes to a recirculatory flow field just ahead of it. The degree of local shielding offered by the detached shield appears minimal.

\section{CONCLUDING REMARKS}

Surveys in the exhaust of an engineering model resistojet developed for space station application have been made using a rotary pitot probe and a rotary quartz crystal microbalance. The resistojet operated on $\mathrm{CO}_{2}$ propellant at a mass flow rate of $0.29 \mathrm{~g} / \mathrm{sec}$ in both unheated and heated flow $(405 \mathrm{~W})$. It is apparent from the measurements of local flow angle in the near field of the nozzle exit plane that an existing conical plume shield does not wholly prevent the viscous boundary layer flow from expanding into the backflow region and that the expansion in this region is not source-like in nature. However, measurements with a rotary QCM indicated that the absolute levels of back flux were very low, on the order of $7 \times 10^{-7} \mathrm{~g} / \mathrm{cm}^{2}-\mathrm{sec}$ or less. When related to the total thruster mass flow rate, the backflux is a factor of 2-8 lower than that observed in a previous investigation of $\mathrm{CO}_{2}$ expansion from a standard conical nozzle. It was not possible to evaluate the level of backflux from the resistojet without the existing conical shield. Also, it is noteworthy that the absolute levels of backflux from the engineering model resistojet are at least one to two orders of magnitude lower than that of monopropellant and bipropellant engines. A circular disk placed at the edge of the existing shield with the intent of simulating an infinitely thick lip further reduced the backflow expanding beyond $90^{\circ}$ by a factor of 2. Lastly, a detached shield located upstream of the thruster exit demonstrated a small degree of local shielding. However, the presence of a nonpumping surface in the backflow region appears to create a recirculatory flow field just ahead of it. Further work is needed to quantify the merits of local shielding.

The exhaust flow field of the engineering model resistojet has not been fully characterized. A detailed experimental evaluation of the interior nozzle flow field is needed to accurately define the gasdynamic processes occurring in this particular nozzle configuration. It is suggested by the authors that the unusual nozzle configuration may aid in the growth of the subsonic portion of the boundary layer, and that it is this subsonic portion which is contributing to the backflux. Further studies of this nozzle configuration 
and perhaps other nozzles are required to fully understand the nature and consequences of the highly viscous resistojet flow.

\section{ACKNOWLEDGEMENT}

The research reported herein was performed by personnel of Calspan Field Services, Inc., operating contractor for the aerospace flight dynamics test facilities, at the Arnold Engineering Development Center under NASA Contract C-30004-J.

\section{REFERENCES}

1. Fester, D., Bicknell, B.,Wilson, S., and Lydon, M., "Space Station Integrated Propulsion and Fluid Systems Study," AIAA Paper 88-3289, July 1988.

2. Bailey, A. B. and Price, L. L., "Flow Field Mapping of Carbon Dioxide Nozzle Expansion into Vacuum," AEDC-TR-85-26, July 1985.

3. Bailey, A. B., Price, L. L., et al, "Flow Field Mapping of Gas/Particle Nozzle Expansion Into Vacuum," AEDC-TR-84-38, July 1985.

4. Zana, L. M., Hoffman, D. J., Breyley, L. R., and Serafini, J. S., "An Analytical and Experimental Investigation of Resistojet Plumes," AIAA Paper 87-0399, January 1987.

5. Breyley, L. R., Hoffman, D. J., Zana,L. M., and Serafini, J. S.,"Effect of Nozzle Geometry on the Resistojet Exhaust Plume," AIAA Paper 87-2121, June 1987.

6. Pugmire,T. K., Cann, G. L., Heckert,B., and Sovey, J. S., "A 10,000 Hour Multipropellant Engine for Space Station Auxiliary Propulsion," AIAA Paper 86-1403, June 1986.

7. Morren, W. E., Hay, S. S., Haag, T. W., and Sovey, J. S., "Preliminary Performance Characterization of an Engineering Model Multipropellant Resistojet for Space Station Application," NASA TM 100113, 1987.

8. Chirivella, J. E., "Mass Flux Measurements and Correlations in the Back Flow Region of a Nozzle Plume," AIAA Paper 73-731, July 1973.

9. Chirivella, J. E., "Hydrazine Engine Plume Contamination Mapping," AFRPLTR-75-16, October 1975.

10. Graybeal, G.A., "Impact Probe Rarefaction Effects Measured in $\mathrm{CO}_{2}$ : Free Jet Expansions," University of Virginia, UVA-ER-741-82U, March 1982.

11. Cooper, G.K., Jordan, J.L., and Phares, W.J., "Analysis Tool for Application to Ground Testing of Highly Underexpanded Nozzles," AIAA Paper 87-2015, June 1987.

12. Alt, R.E., "Bipropellant Engine Plume Contamination Program," AEDC-TR-7928-Vol-I, December 1979. 
TABLE I. - OPERATING AND PERFORMANCE CHARACTERISTICS OF THE QUARTZ CRYSTAL MICROBALANCE

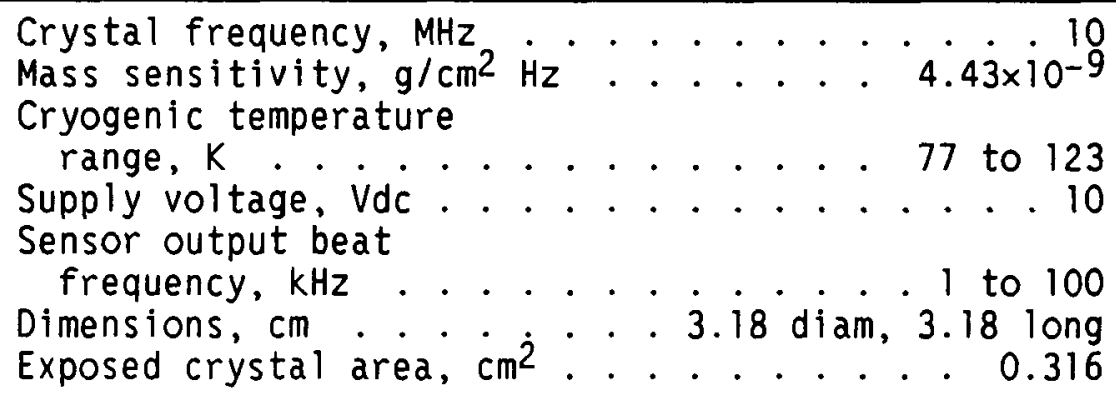

TABLE II. - ENGINEERING RESISTOJET OPERATING CHARACTERISTICS WITH $\mathrm{CO}_{2}$ PROPELLANTa

\begin{tabular}{|l|r|r|}
\hline & \multicolumn{1}{|c|}{$\begin{array}{c}\text { Cold } \\
\text { flow }\end{array}$} & \multicolumn{1}{|c|}{$\begin{array}{c}\text { Heated } \\
\text { flow }\end{array}$} \\
\hline Heater resistance, $\Omega$ & 0.34 & 0.78 \\
Heater current, $\mathrm{H}$ & 0 & 23.1 \\
Heater power, $\mathrm{W}$ & 0 & 418 \\
Mass flow rate, g/sec & 0.308 & 0.297 \\
Inlet pressure, N/m2 & $1.50 \times 105$ & $2.76 \times 105$ \\
Measured thrust, g & 19.6 & 35.1 \\
Specific impulse, sec & 63.6 & 119.0 \\
Overall thrust & & \\
efficiency, percent & 91.4 & 43.0 \\
\hline
\end{tabular}

aRef. 7. 
TABLE III - - COMPARISON OF BACK FLUX DATA

\begin{tabular}{|c|c|c|c|c|}
\hline & $\begin{array}{l}\text { Engineering } \\
\text { model } \\
\text { resistojet } \\
\text { (present) }\end{array}$ & $\begin{array}{c}\text { Conical } \\
\text { nozzle } \\
\text { expansiona }\end{array}$ & $\begin{array}{l}\text { Simulated } \\
\text { hydrazine } \\
\text { thrusterb }\end{array}$ & $\begin{array}{l}\text { Bipropellant } \\
\text { enginec }\end{array}$ \\
\hline$P_{0}, N / m^{2}$ & $27 \times 10^{5}$ & $1.5 \times 10^{5}$ & $2.7 \times 10^{5}$ & $7 \times 10^{6}$ \\
\hline$\dot{\mathrm{m}}, \mathrm{g} / \mathrm{sec}$ & 0.295 & 0.68 & 0.34 & $\begin{array}{l}\sim 5 \text { to } 7 \mathrm{~g} / \mathrm{sec} \\
(100 \mathrm{msec} \mathrm{pulse})\end{array}$ \\
\hline Nozzle type & $\begin{array}{l}\text { Cone/trumpet } \\
+45^{\circ} \text { shield }\end{array}$ & $\begin{array}{l}\text { Conical, } \\
\text { thick lip }\end{array}$ & Conical & Contoured \\
\hline $\begin{array}{l}\text { Nozzle area } \\
\text { ratio }\end{array}$ & $d_{2500}$ & 360 & 60 & 50 to 100 \\
\hline $\begin{array}{l}\text { Collected } \\
\text { gas species }\end{array}$ & $\mathrm{CO}_{2}$ & $\mathrm{CO}_{2}$ & $\mathrm{~N}_{2}$ & $\begin{array}{l}\text { Condensible } \\
\text { exhaust products } \\
\text { of } \mathrm{N}_{2} \mathrm{O}_{4} / \mathrm{MMH}\end{array}$ \\
\hline $\begin{array}{c}\text { Angle off } \\
\text { centerline, } \\
\text { deg }\end{array}$ & \multicolumn{4}{|c|}{ Absolutee $(d M / d \Omega)_{\theta}, g / s e c \cdot s r$} \\
\hline $80^{\circ}$ & $1 \times 10^{-4}$ & $4 \times 10^{-3}$ & $1 \times 10^{-3}$ & $1 \times 10^{-2}$ \\
\hline $110^{\circ}$ & $9 \times 10^{-5}$ & $3 \times 10^{-4}$ & $\begin{array}{l}6 \times 10^{-4} \\
+2 \times 10^{-3}\end{array}$ & $1 \times 10^{-3}$ \\
\hline $140^{\circ}$ & ----------- & ------- & $3 \times 10^{-4}$ & $1 \times 10^{-4}$ \\
\hline $\begin{array}{l}\text { Angle off } \\
\text { centerline, } \\
\text { deg }\end{array}$ & \multicolumn{2}{|c|}{ Ratio of $\dot{M} / \dot{m}$} & & \\
\hline $80^{\circ}$ & $1 \times 10^{-6}$ & $8 \times 10^{-6}$ & & \\
\hline $110^{\circ}$ & $3 \times 10^{-7}$ & $6 \times 10^{-7}$ & & \\
\hline
\end{tabular}

aRef. 3 .

bef. 9, Fig. 23(a).

CRef. 12 .

dArea ratio considering conical shield exit plane.

Where $(d \dot{M} / d \Omega)_{\theta}=M r^{2} \cos \varphi, g / s \cdot s r$. 


\section{CRIGINAL PAGE IS \\ OF. POOR QUALTY}

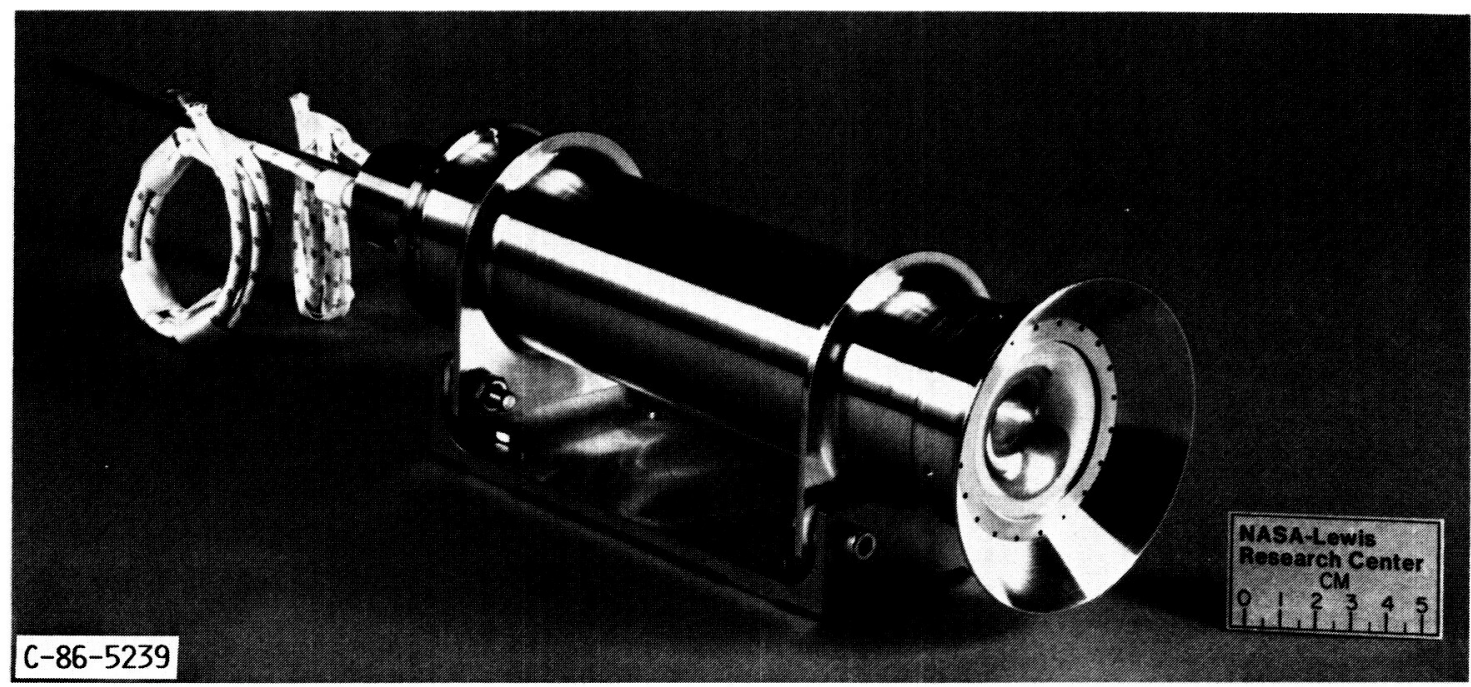

(a) MODEL 1.

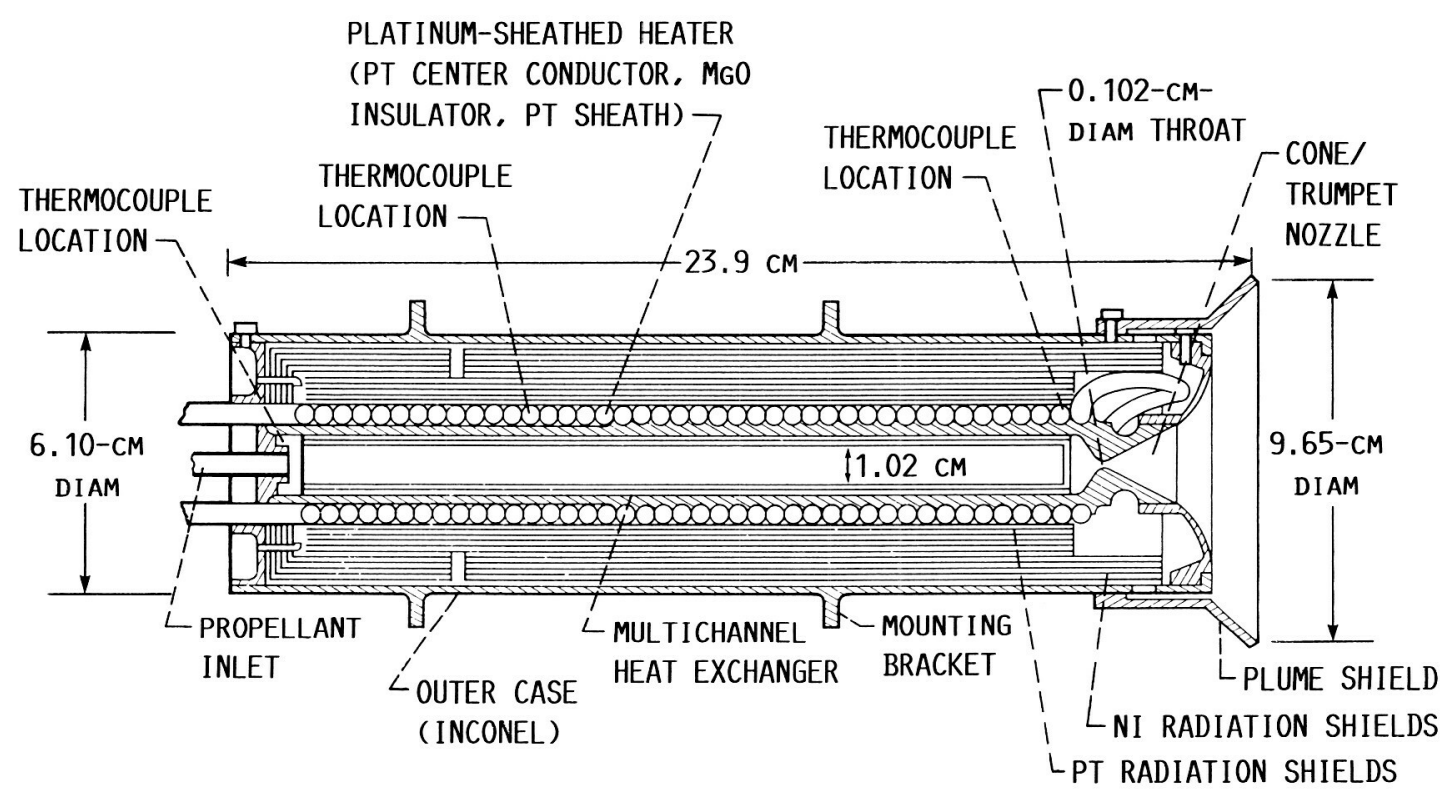

(b) CUTAWAY SCHEMATIC.

Fig. 1. - ENGINEERING MODEL RESISTOJET DEVELOPED FOR SPACE STATION APPLICATION. 


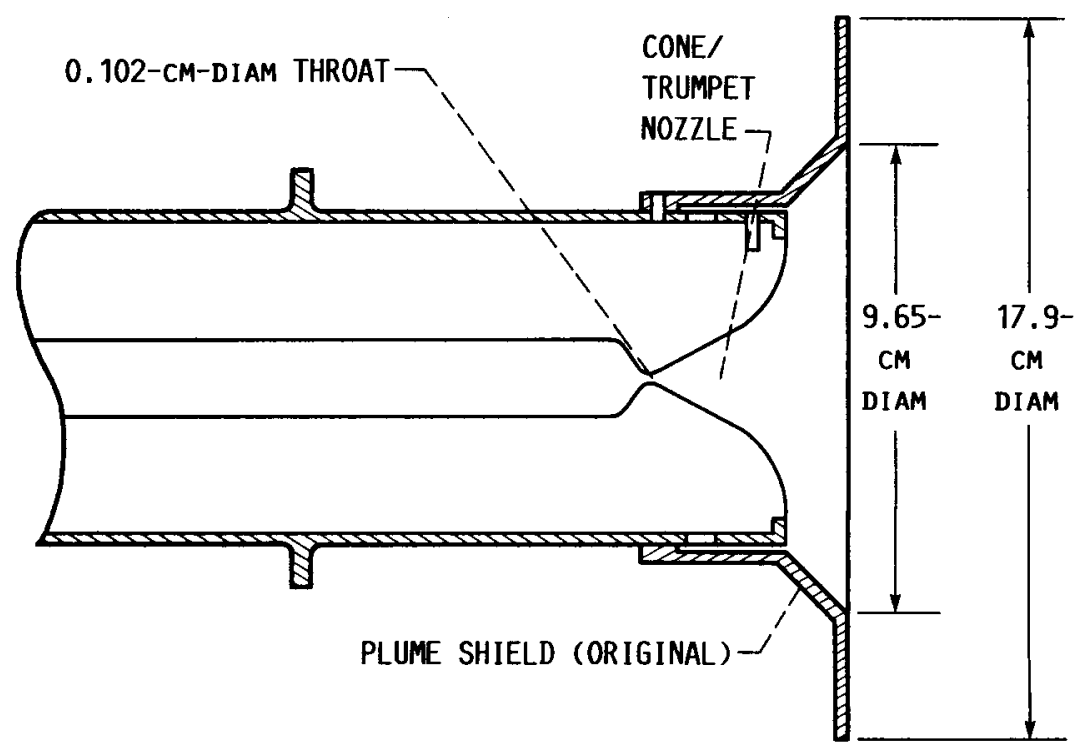

(a) CONICAL SHIELD WITH ADDED CIRCULAR DISK.

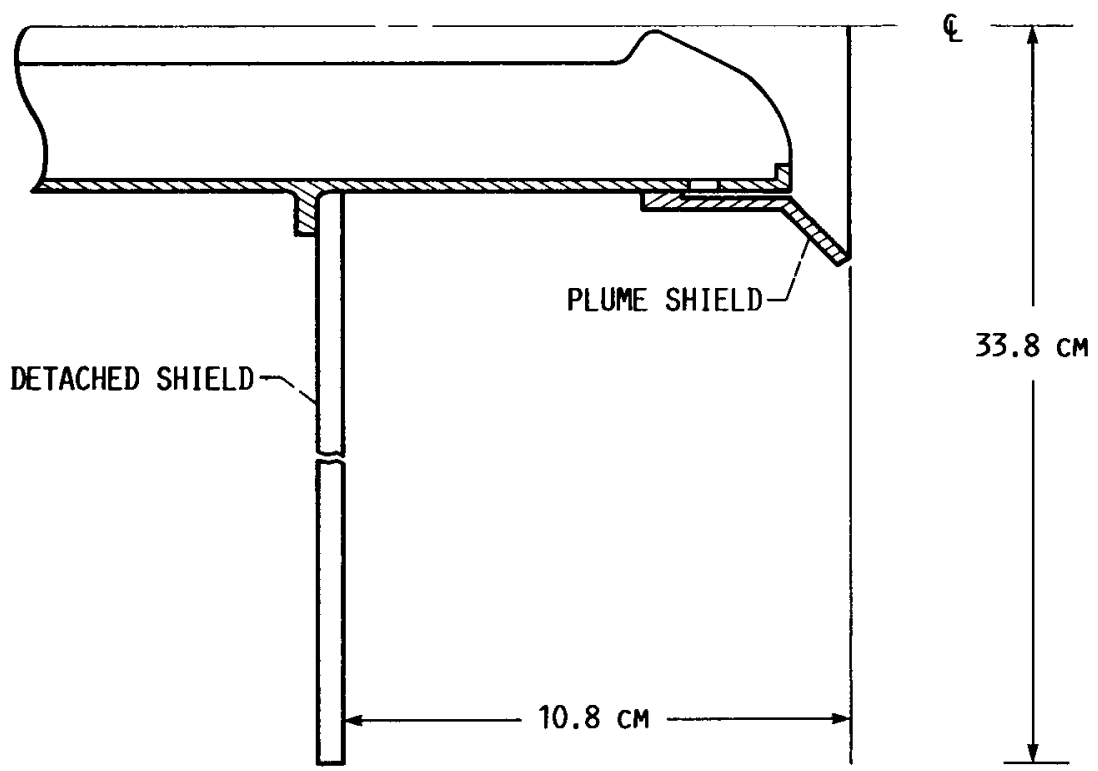

(b) DETACHED SHIELD CONFIGURATION.

FIG. 2. - PLUME SHIELD CONFIGURATIONS. 


\section{ORIGINAL PAGE IS}

OF. POOR QUALITY

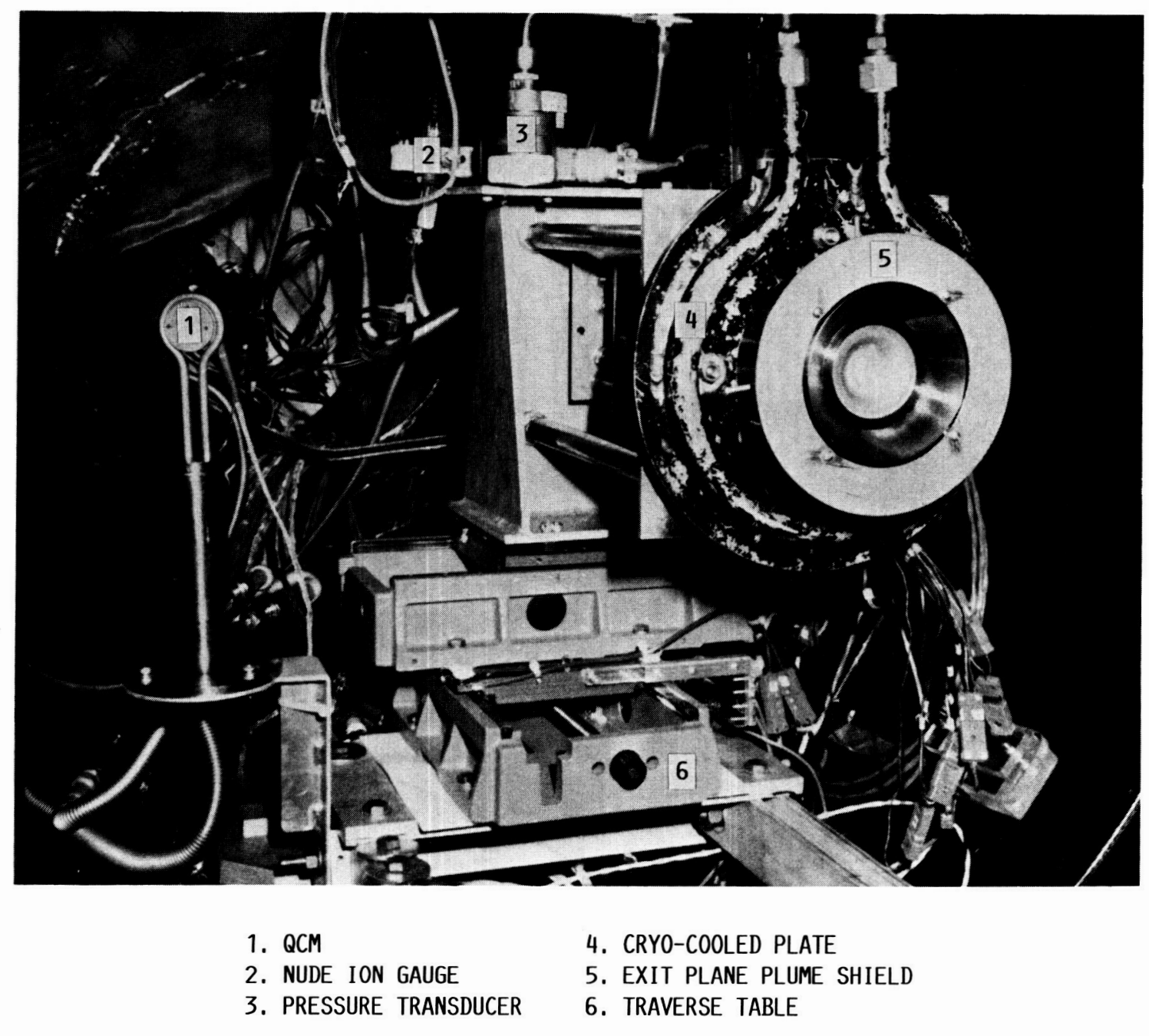

FIG. 3. - RESISTOJET INSTALLED IN THE RESEARCH VACUUM CHAMBER AT ARNOLD ENGINEERING DEVELOPMENT CENTER. 


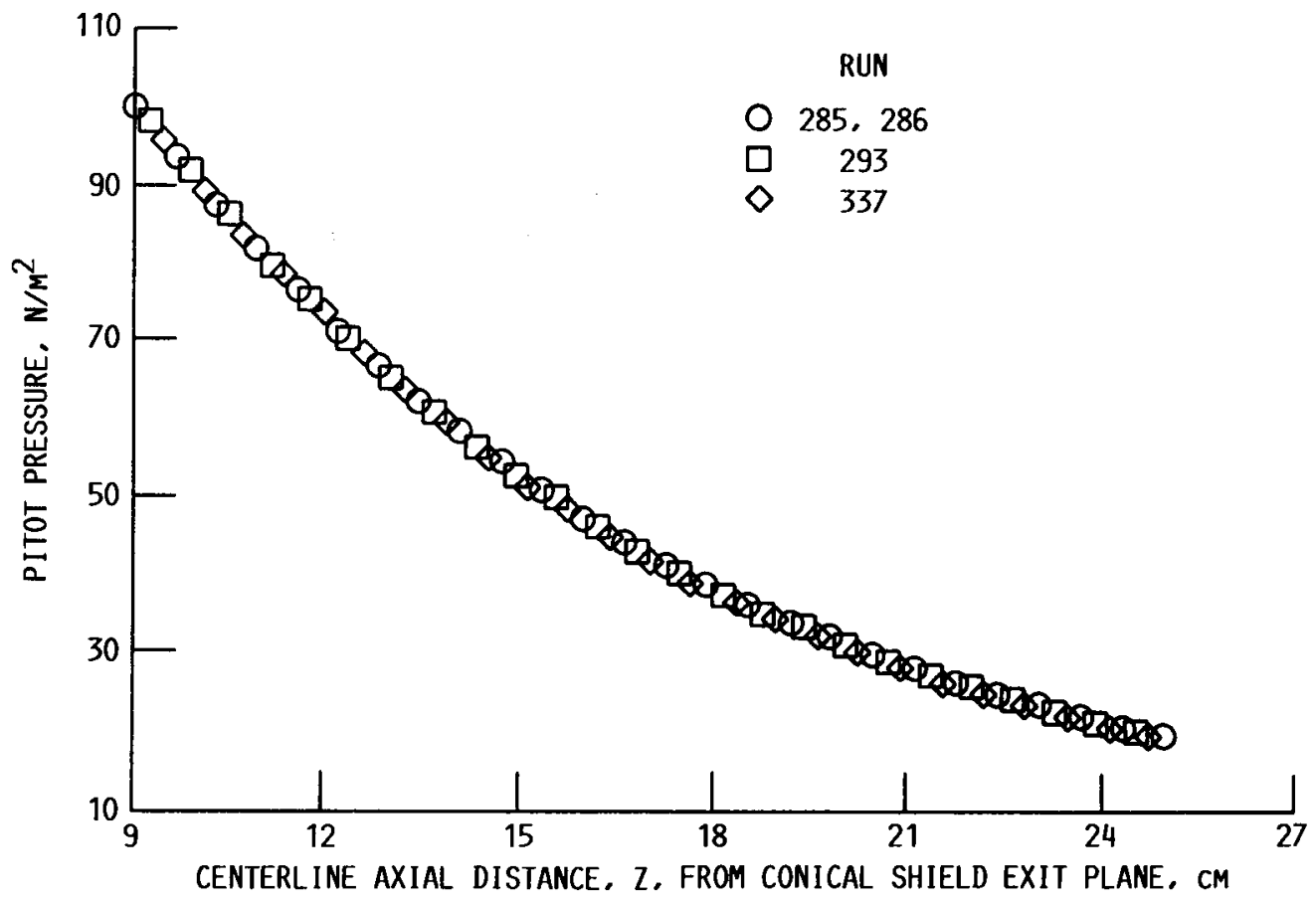

FI6. 4. - DEMONSTRATION OF REPEATABILITY OF CENTERLINE PITOT PRESSURE VARIATION WITH AXIAL POSITION (HEATED FLOW, $D_{p}, 0.64 \mathrm{~cm}$ ).

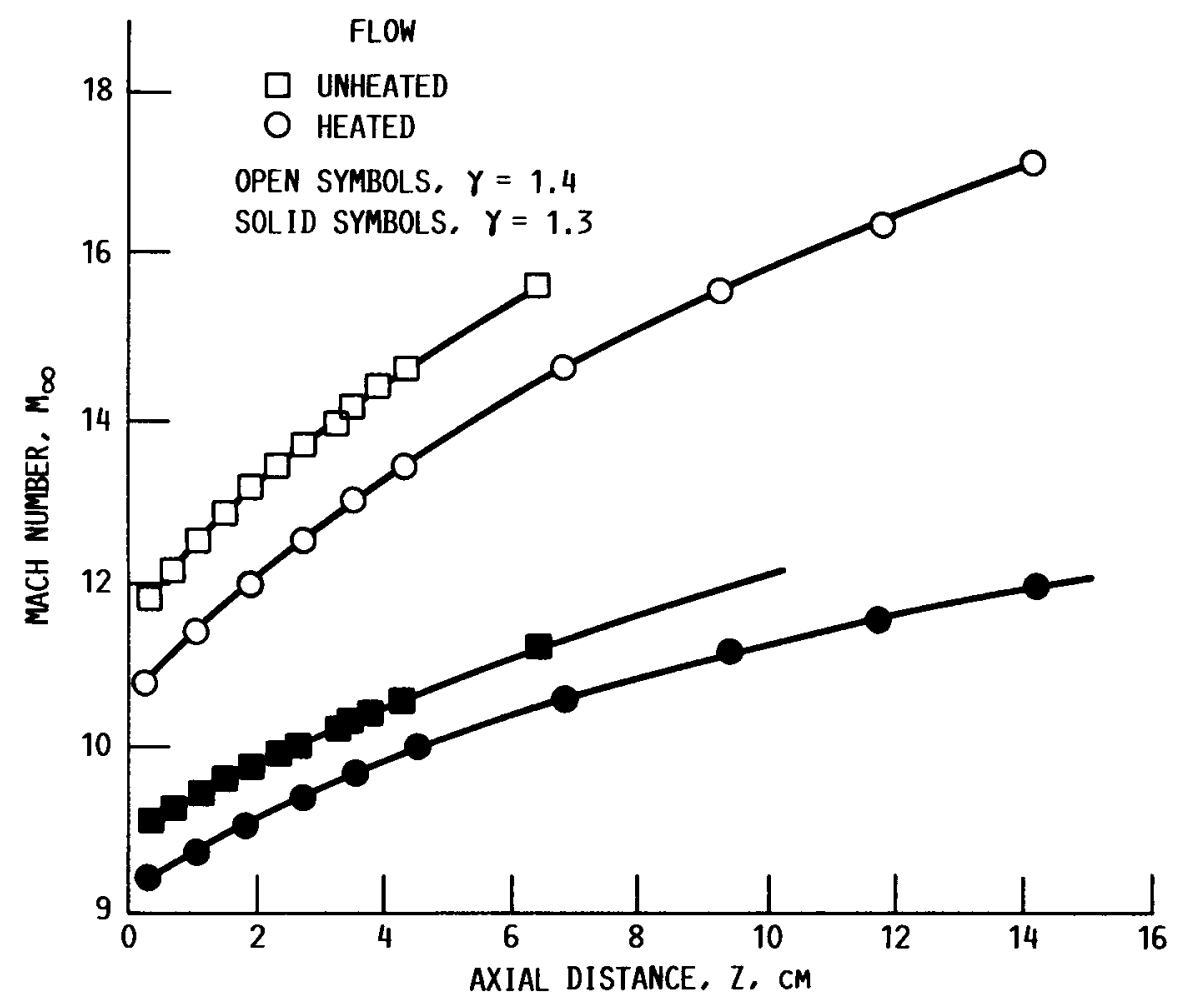

FIG. 5. - CENTERLINE MACH NUMBER VARIATION WITH AXIAL DISTANCE (HEATED AND UNHEATED FLOW; CONICAL SHIELD EXIT PLANE AT AXIAL DISTANCE $Z=0$ ). 


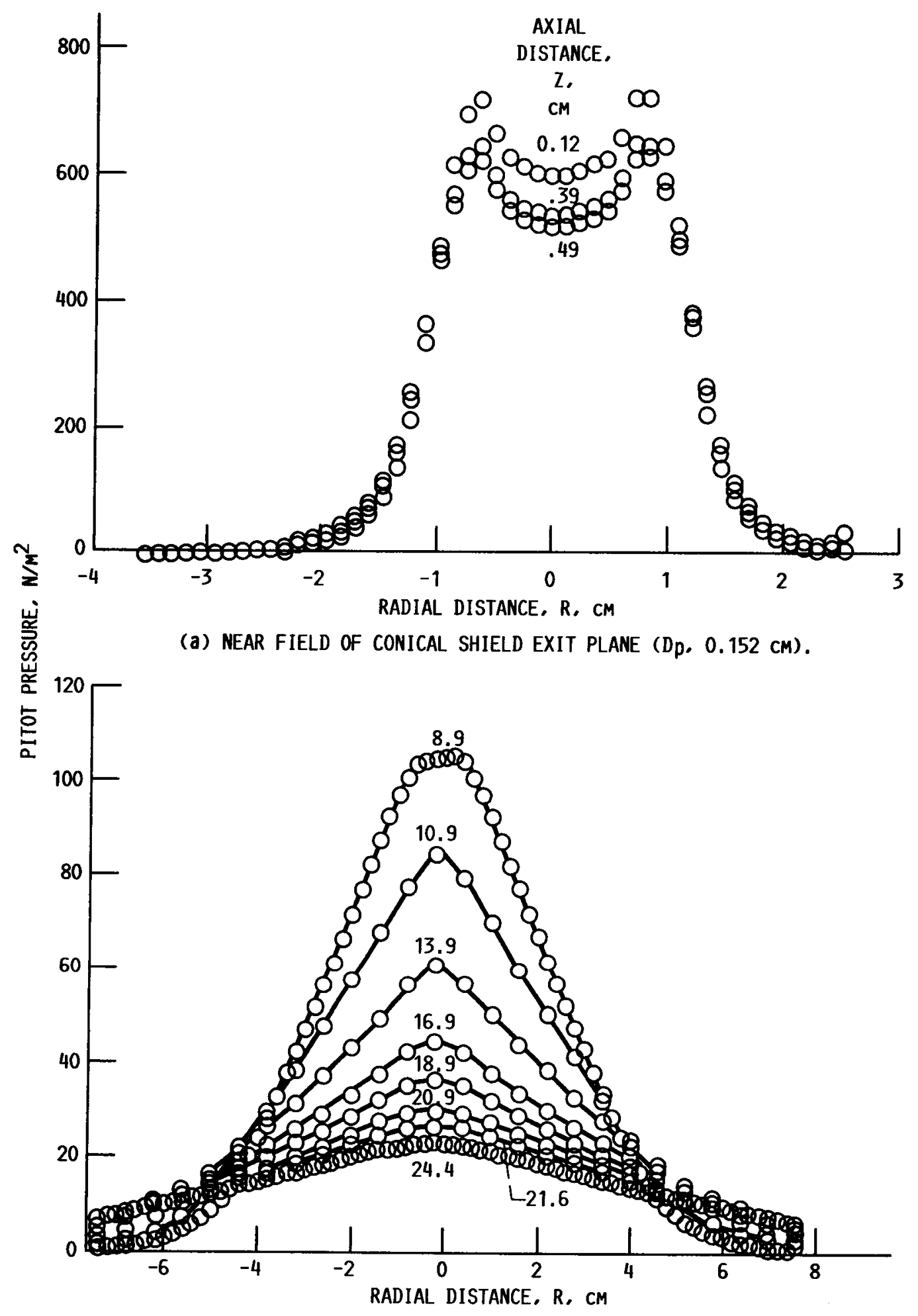

(b) DOWNSTREAM OF CONICAL SHIELD EXIT PLANE ( $\left.D_{p}, 0.64 \mathrm{~cm}\right)$.

FIG. 6. - RADIAL PITOT PRESSURE PROFILES AT VARIOUS AXIAL LOCATIONS (HEATED FLOW). 


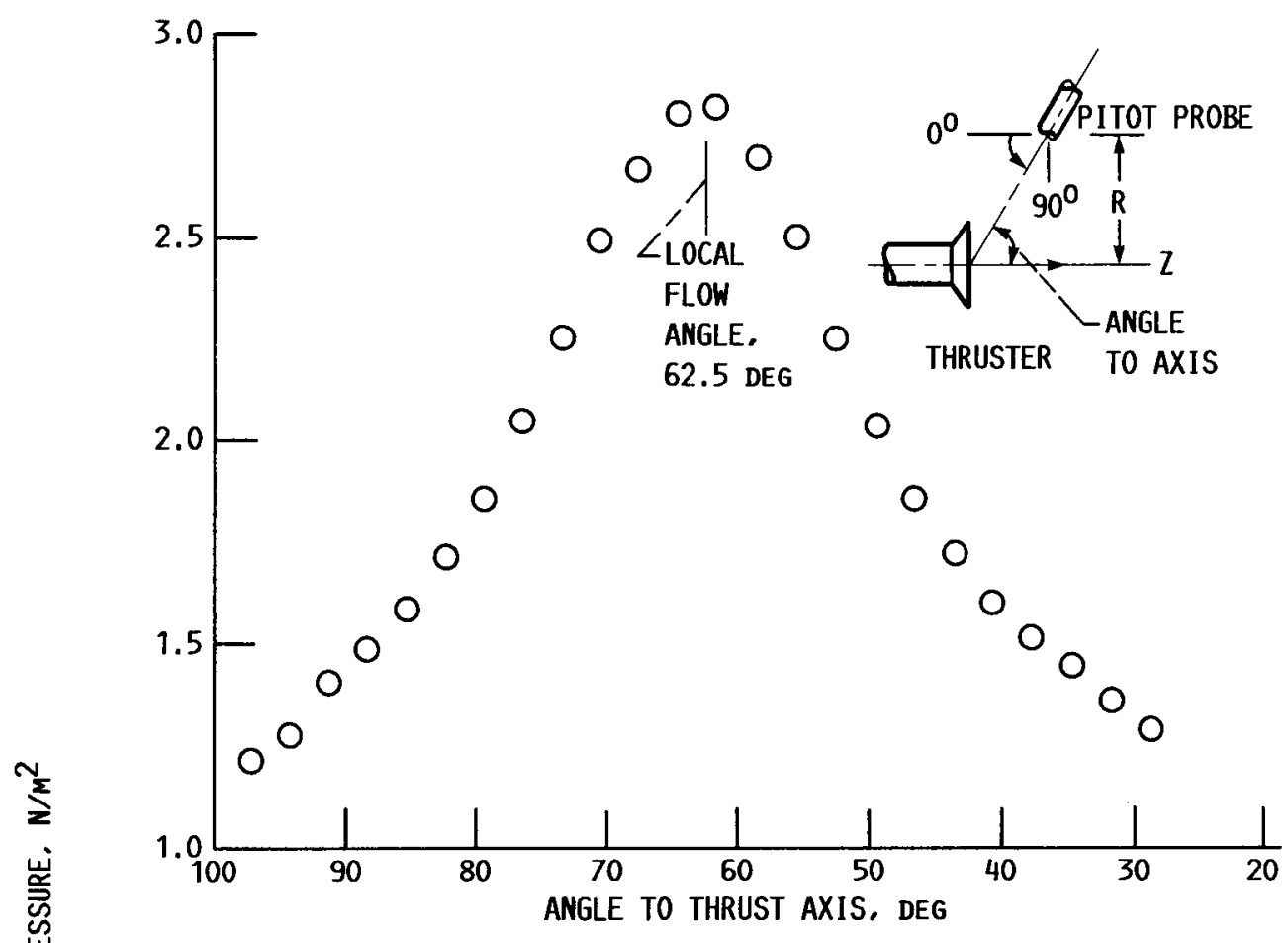

(a) LOCATION: AXIAL DISTANCE, $Z, 0.12 \mathrm{~cm}$; RADIAL DISTANCE,

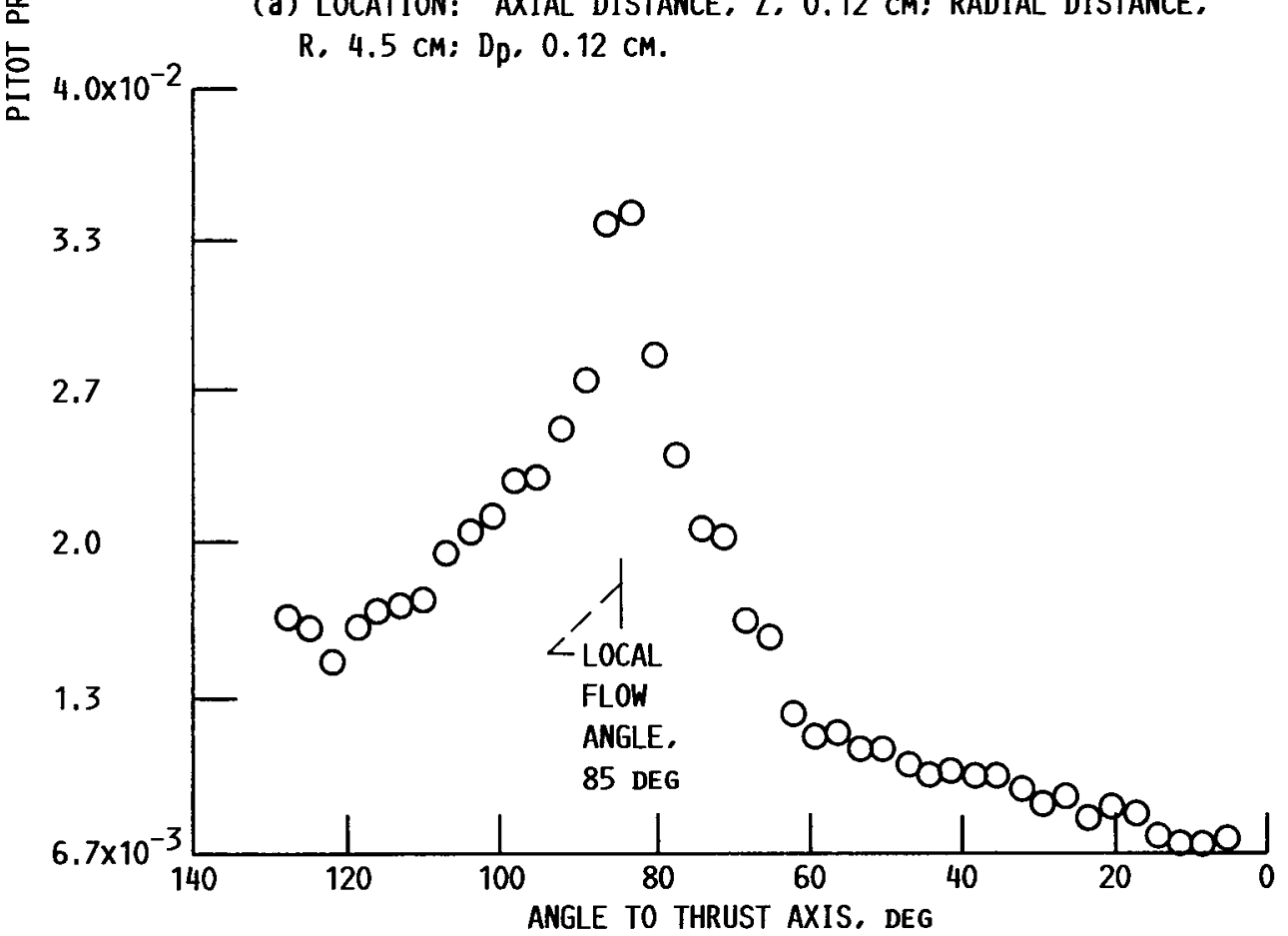

(b) LOCATION: AXIAL DISTANCE, $2,0.64 \mathrm{cM}$; RADIAL DISTANCE,

R. $10.9 \mathrm{cM}: \mathrm{D}_{\mathrm{p}}, 0.64 \mathrm{cM}$.

FIG. 7. - VARIATION OF PITOT PRESSURE WITH ANGLE TO THRUST AXIS (HEATED FLOW: CONICAL SHIELD ONLY). 


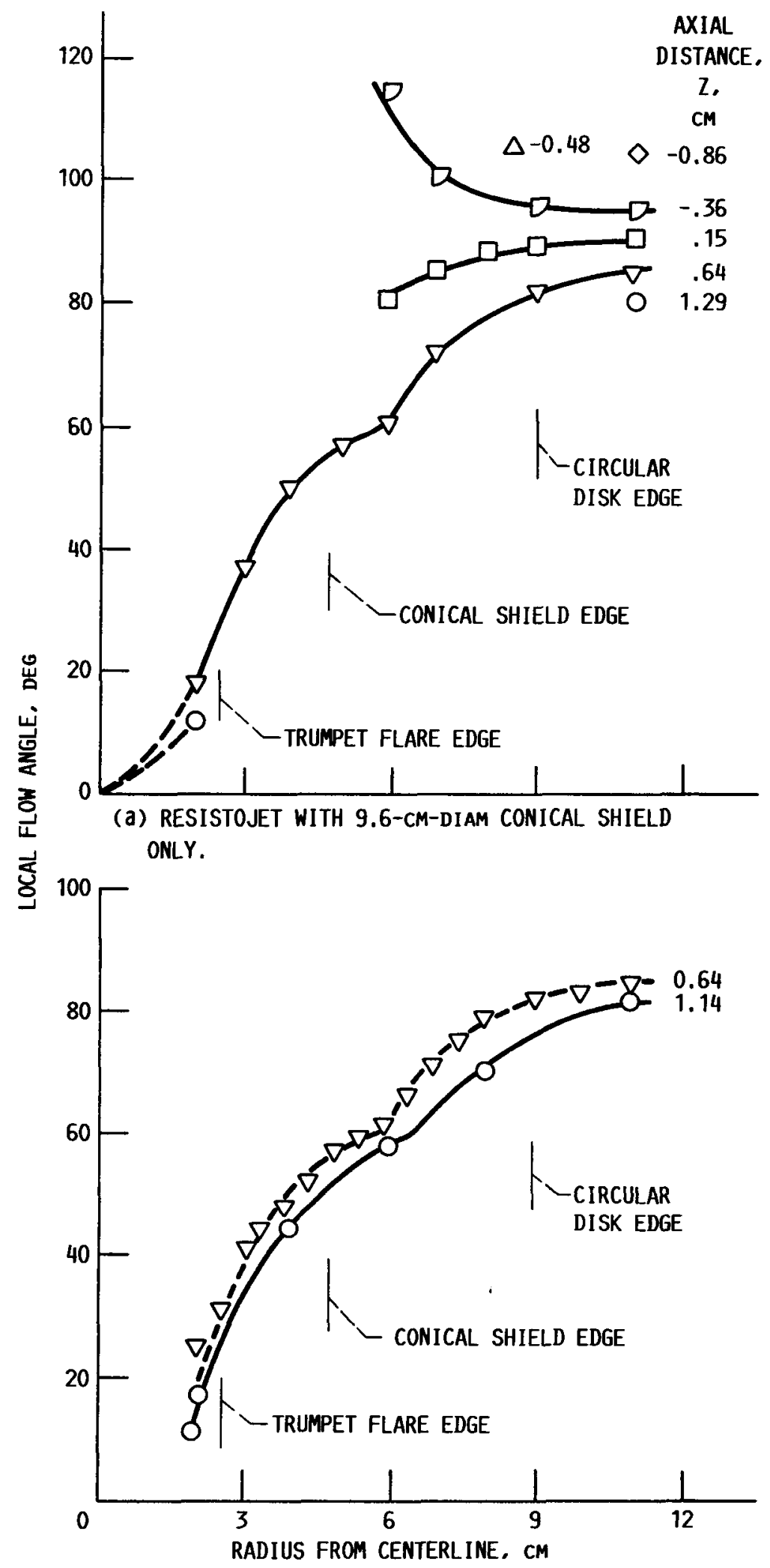

(b) RESISTOJET WITH ADDITIONAL 17.8-CM-DIAM SHIELD. (DASHED LINE IS CONICAL SHIELD ONLY DATA: FLOW ANGLE INDETERMINATE WITH PITOT PROBE AT $-0.36 \mathrm{~cm}$ UPSTREAM WITH (IRCULAR DISK IN PLACE.)

FIG. 8. - LOCAL FLOW ANGLE VARIATION WITH AXIAL AND RADIAL DISTANCE (HEATED FLOW). 


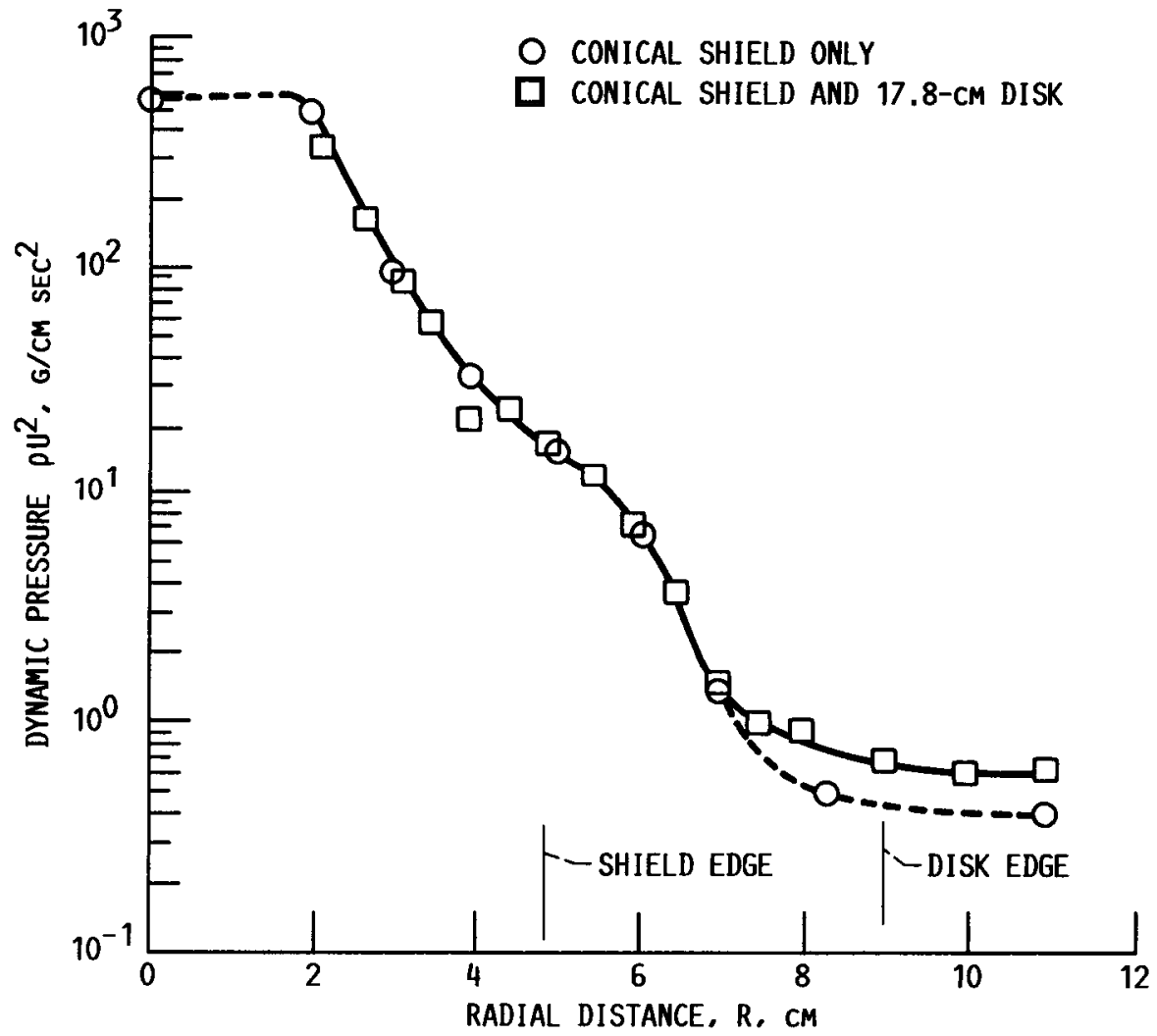

FIG. 9. - DYNAMIC PRESSURE PROFILES AS FUNCTION OF RADIAL DISTANCE, WITH AND WITHOUT AN ADDED CIRCULAR DISK (AXIAL DISTANCE, Z, $0.64 \mathrm{~cm}$ ). 


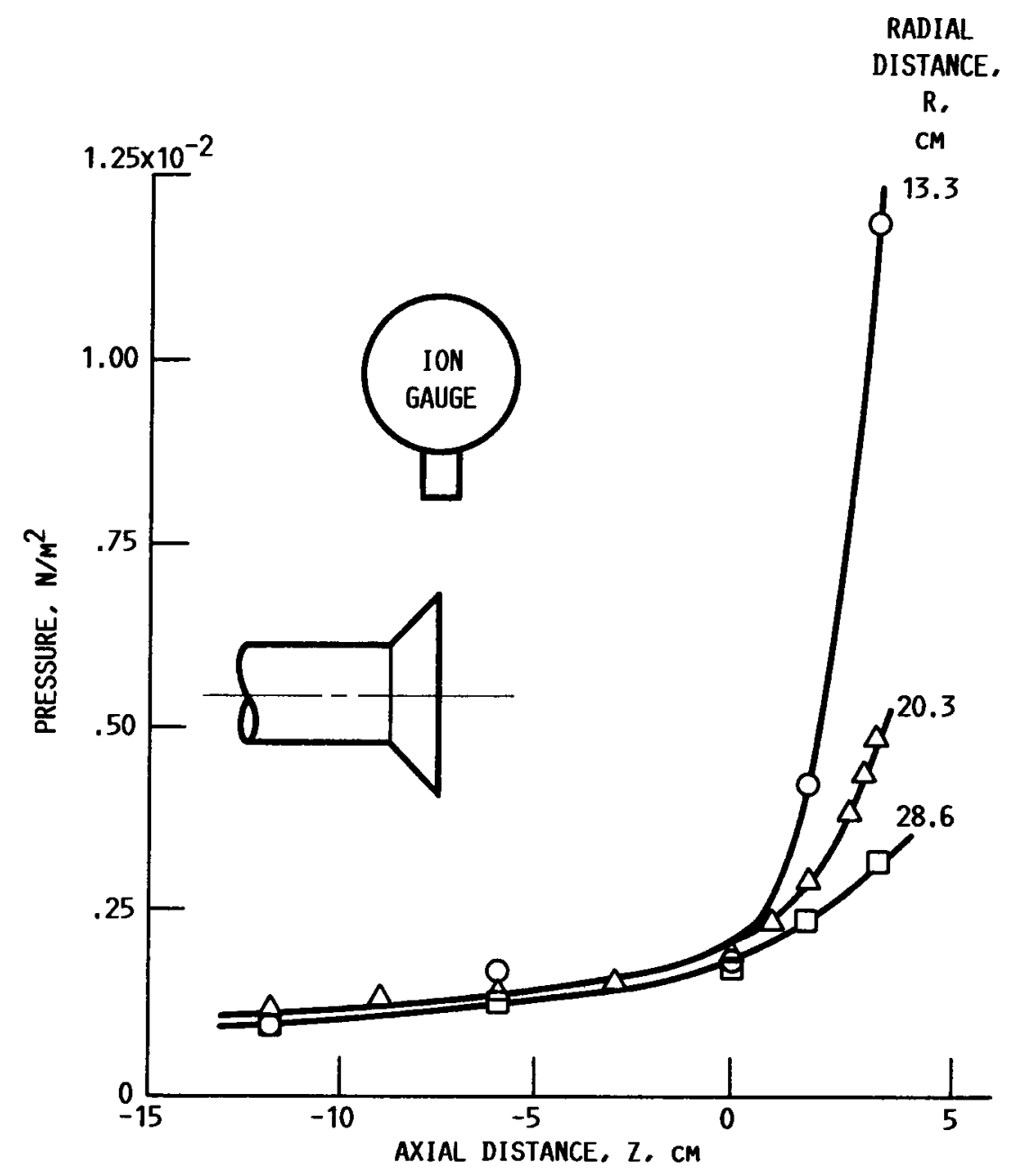

FIG. 10. - ION GAUGE PRESSURE VARIATION WITH AXIAL AND RADIAL DISTANCE (GAUGE NORMAL TO THRUST AXIS; HEATED FLOW: CONICAL SHIELD ONLY). 


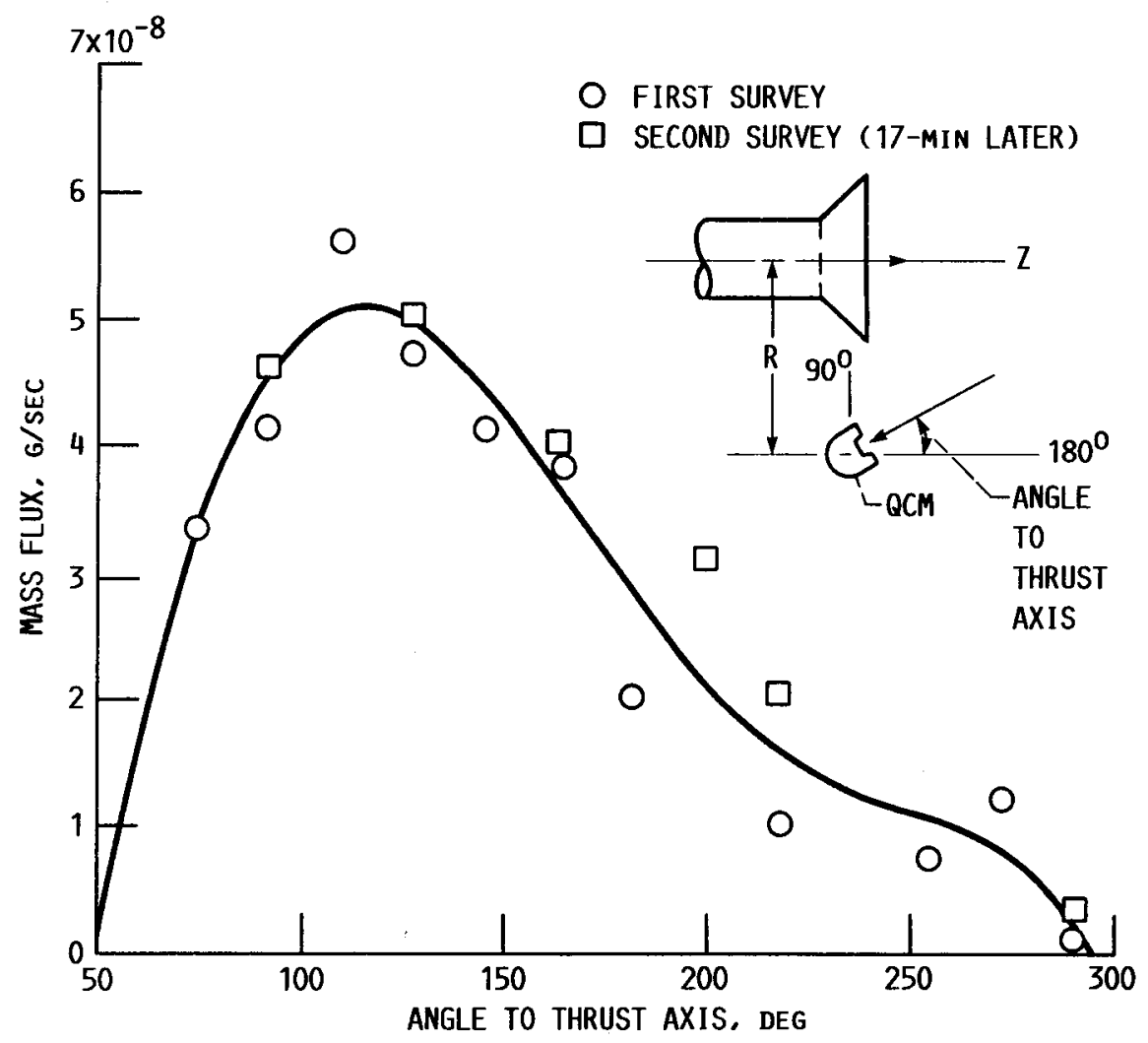

FIG. 11. - REPEATABILITY OF MASS FLUX MEASUREMENTS (MASS FLUX VERSUS ANGLE TO AXIS: RADIAL DISTANCE, R, $38.7 \mathrm{cM}$ : AXIAL DISTANCE, Z, $-17.8 \mathrm{cM})$. 


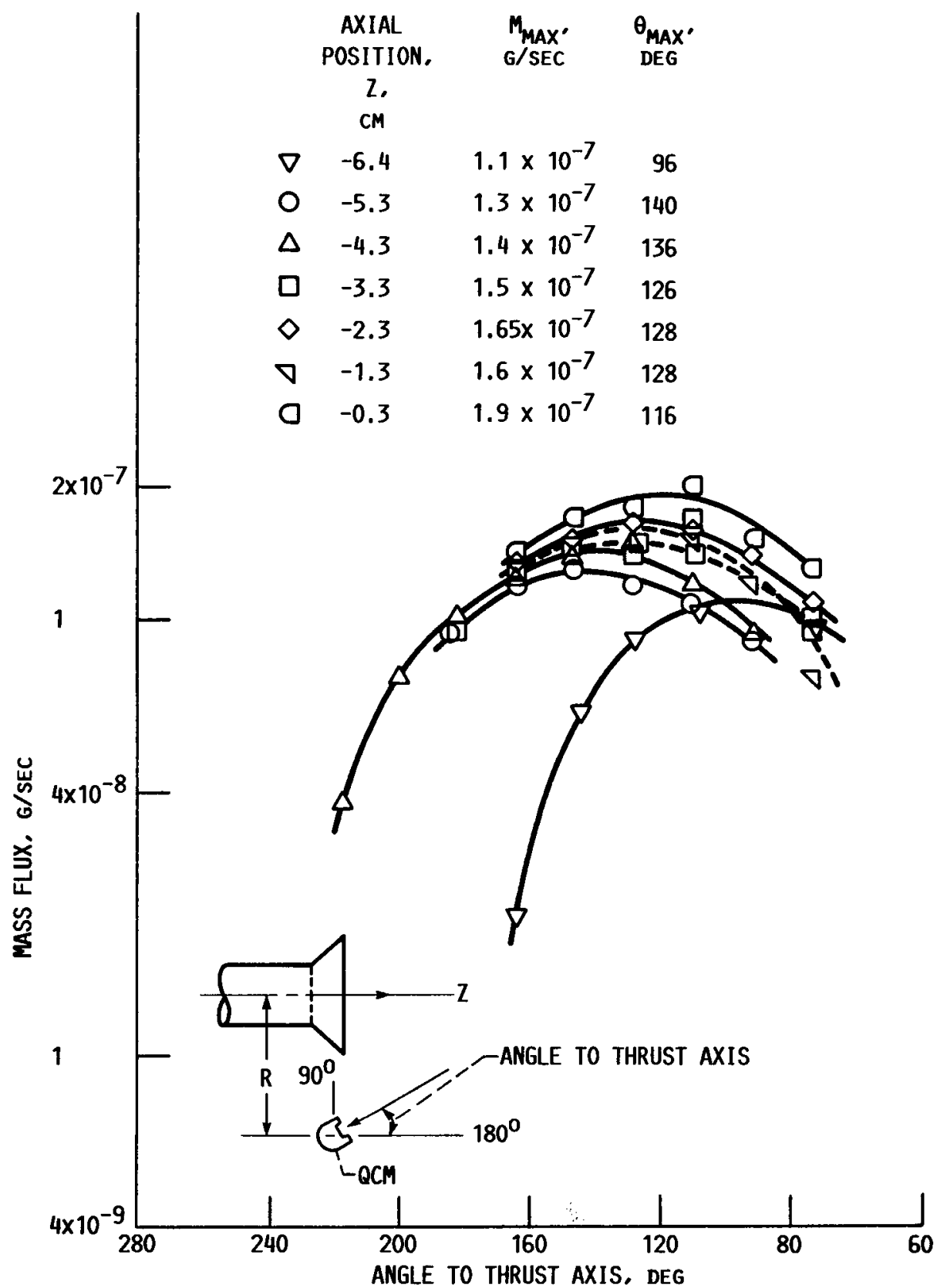

FIG. 12. - VARIATION OF MASS FLUX WITH ANGLE TO THRUST AXIS (FOR VARIOUS AXIAL POSITIONS ( $R, 23.9 \mathrm{cM}$ ); HEATED FLOW: CONICAL SHIELD AND 17.8-CM-DIAM DISK). 


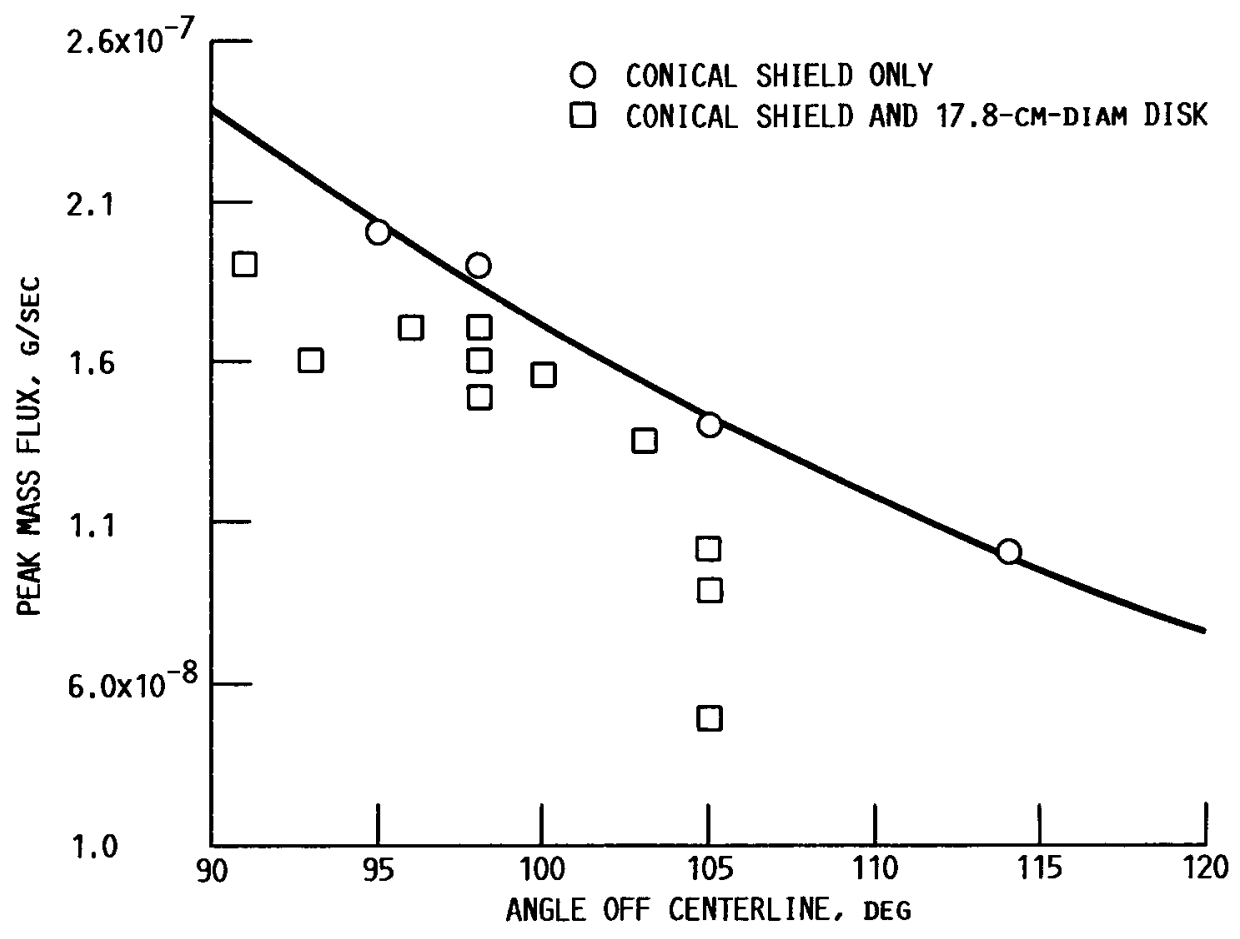

FIG. 13. - MASS FLUX AS FUNCTION OF ANGLE OFF CENTERLINE (RADIAL DISTANCE, R, $23.9 \mathrm{~cm}$ ).

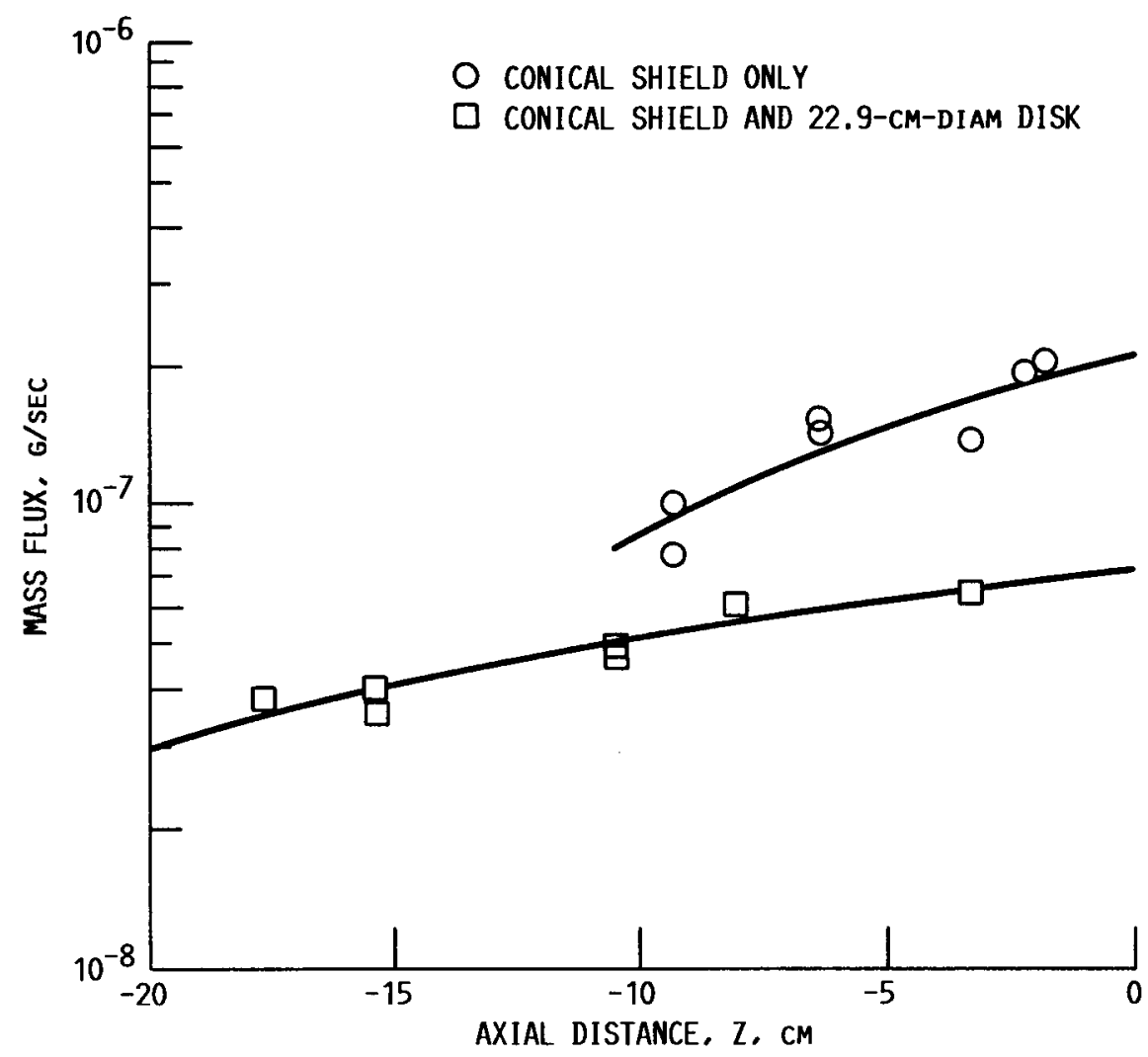

FIG. 14. - MASS FLUX AS FUNCTION OF AXIAL DISTANCE (CONSTANT RADIAL DISTANCE, R, $23.5 \mathrm{cM}$; QCM ANGLE WITH RESPECT TO THRUST AXIS, 146 DEG). 


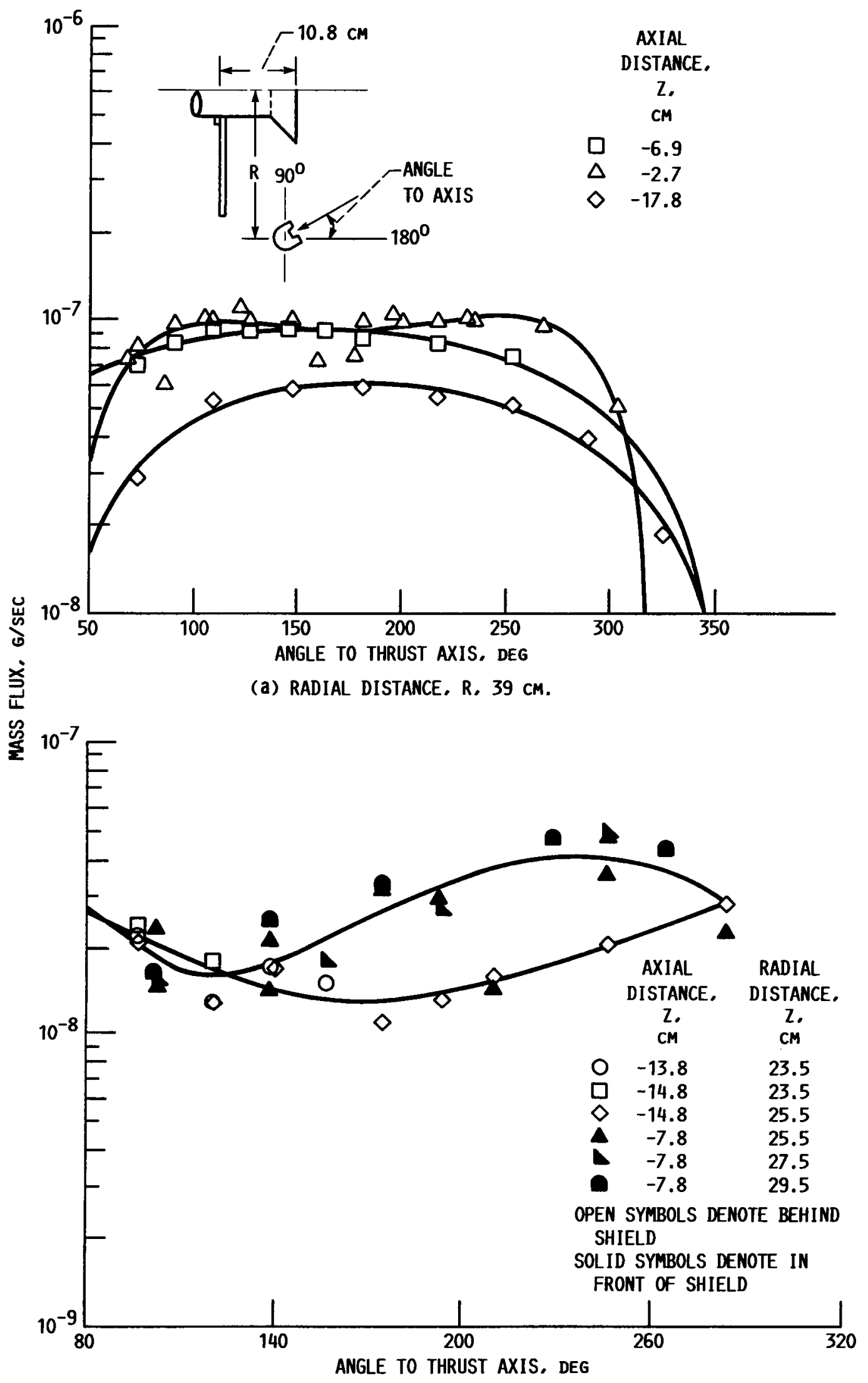

(b) VARIOUS RADIAL DISTANCES.

FIG. 15. - MASS FLUX AS FUNCTION OF ROTARY ANGLE (DETACHED SHIELD LOCATED AT AXIAL DISTANCE $Z=-10.8 \mathrm{~cm}$ ). 


\begin{tabular}{|c|c|c|c|c|c|}
\hline \multicolumn{6}{|c|}{ Report Documentation Page } \\
\hline 1. Report No. & $\begin{array}{l}\text { NASA TM-101363 } \\
\text { IEPC-88-091 }\end{array}$ & \multicolumn{2}{|c|}{ 2. Government Accession No. } & \multicolumn{2}{|c|}{ 3. Recipient's Catalog No. } \\
\hline \multirow{3}{*}{\multicolumn{4}{|c|}{$\begin{array}{l}\text { 4. Title and Subtitle } \\
\text { Experimental Evaluation of Resistojet Thruster Plume Shields }\end{array}$}} & \multirow{2}{*}{\multicolumn{2}{|c|}{ 5. Report Date }} \\
\hline & & & & & \\
\hline & & & & \multicolumn{2}{|c|}{ 6. Performing Organization Code } \\
\hline \multirow{2}{*}{\multicolumn{4}{|c|}{$\begin{array}{l}\text { 7. Author(s) } \\
\text { Lynnette M. Carney and Allan B. Bailey }\end{array}$}} & \multirow{2}{*}{\multicolumn{2}{|c|}{$\begin{array}{l}\text { 8. Performing Organization Report No. } \\
\text { E-4356 }\end{array}$}} \\
\hline & & & & & \\
\hline & & & & \multirow{2}{*}{\multicolumn{2}{|c|}{$\begin{array}{l}\text { 10. Work Unit No. } \\
506-42-31\end{array}$}} \\
\hline \multirow{3}{*}{\multicolumn{4}{|c|}{$\begin{array}{l}\text { 9. Performing Organization Name and Address } \\
\text { National Aeronautics and Space Administration } \\
\text { Lewis Research Center } \\
\text { Cleveland, Ohio 44135-3191 }\end{array}$}} & & \\
\hline & & & & \multicolumn{2}{|c|}{\begin{tabular}{|l|} 
11. Contract or Grant No. \\
\end{tabular}} \\
\hline & & & & \multirow{2}{*}{\multicolumn{2}{|c|}{$\begin{array}{l}\text { 13. Type of Report and Period Covered } \\
\text { Technical Memorandum }\end{array}$}} \\
\hline \multirow{2}{*}{\multicolumn{4}{|c|}{$\begin{array}{l}\text { 12. Sponsoring Agency Name and Address } \\
\text { National Aeronautics and Space Administration } \\
\text { Washington, D.C. 20546-0001 }\end{array}$}} & & \\
\hline & & & & \multicolumn{2}{|c|}{ 14. Sponsoring Agency Code } \\
\hline \multicolumn{6}{|c|}{ 15. Supplementary Notes } \\
\hline \multicolumn{6}{|c|}{$\begin{array}{l}\text { Prepared for the 20th International Electric Propulsion Conference cosponsored by the DGLR, AIAA, and JSASS, } \\
\text { Garmisch-Partenkirchen, W. Germany, October 3-6, 1988. Lynnette M. Carney, NASA Lewis Research Center; } \\
\text { Allan B. Bailey, Calspan Corporation, Arnold Engineering Development Center, Arnold Air Force Base, } \\
\text { Tennessee } 37389 .\end{array}$} \\
\hline \multicolumn{6}{|c|}{$\begin{array}{l}\text { The exhaust of an engineering model resistojet has been investigated using rotary pitot probes and a rotary quartz } \\
\text { crystal microbalance. The resistojet operated on } \mathrm{CO}_{2} \text { propellant at a mass flow rate of } 0.29 \mathrm{~g} / \mathrm{sec} \text { in both heated } \\
\text { and unheated flows. Measurements of local flow angles in the near field of a conical plume shield indicated that the } \\
\text { shield was not wholly effective in confining the flow to the region upstream of its exit plane. However, the absolute } \\
\text { levels of the measured mass flux into the backflow region were very low, on the order of } 7 \times 10^{-7} \mathrm{~g} / \mathrm{cm}^{2}-\mathrm{sec} \text { or } \\
\text { less. The use of a circular disk at the exit plane of the existing conical shield showed some benefit in decreasing } \\
\text { the amount of backflow by a factor of } 2 \text {. Lastly, a detached shield placed upstream of the resistojet exit plane } \\
\text { demonstrated a small degree of local shielding for the region directly behind it. }\end{array}$} \\
\hline \multicolumn{3}{|c|}{ 17. Key Words (Suggested by Author(s)) } & \multicolumn{3}{|c|}{ 18. Distribution Statement } \\
\hline \multicolumn{3}{|c|}{$\begin{array}{l}\text { Resistojet; Plumes; Plume contamination; Electrothermal } \\
\text { thrusters; Electric propulsion }\end{array}$} & \multicolumn{3}{|c|}{$\begin{array}{l}\text { Unclassified-Unlimited } \\
\text { Subject Category } 20\end{array}$} \\
\hline \multicolumn{2}{|c|}{ 19. Security Classif. (of this report) } & \multicolumn{2}{|c|}{ 20. Security Classif. (of this page) } & 21. No of pages & 22. Price* \\
\hline & Unclassified & Unc & ssified & 26 & A03 \\
\hline
\end{tabular}

